\title{
Arranjos espaciais e especificações técnicas para ambientes de aprendizagem adequados a práticas educacionais com blended learning
}

\author{
Spatial layouts and technical specifications for learning \\ environments suitable for blended learning educational \\ practices
}

\begin{abstract}
Thaisa Sampaio Sarmento
Vilma Villarouco

Alex Sandro Gomes

Resumo

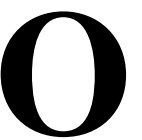

s sistemas educacionais no Brasil renovam-se para se adequar a padrões internacionais de qualidade em educação. Esse é um esforço grande frente aos problemas de diferentes naturezas encontrados na rede pública de escolas brasileiras, que deveria funcionar em plenas condições de infraestrutura física, recursos humanos, didáticos e digitais. Ações de modernização das estratégias educacionais por meio da adoção de tecnologias da informação e comunicação (TICs) apontam para a tendência de implantação da educação híbrida, ou blended learning, em sistemas tradicionais de ensino. Diante disso, esta pesquisa discute os leiautes padrões de ambientes de aprendizagem propostos em referências nacionais e as inovações sugeridas em estudos científicos sobre ambientes de aprendizagem inovadores, no Brasil e no exterior. A pesquisa é de cunho qualitativo, e seu paradigma é o design science research associado a métodos de avaliação e de projeto ergonômico para o ambiente construído. Os resultados apontam para o desenvolvimento de propostas inovadoras de arranjos espaciais de ambientes de aprendizagem, nos quais foram aplicados conceitos de flexibilidade para atender às múltiplas formas de aprendizagem, aplicando dimensionamento ergonômico e especificações técnicas de elementos construtivos, de sistemas e de condicionamento ambiental.

Palavras-chave: Ambiente de aprendizagem. Especificações técnicas. Blended learning.

${ }^{1}$ Thaisa Sampaio Sarmento Universidade Federal de Alagoas Maceió - AL - Brasil

${ }^{2}$ Vilma Villarouco Universidade Federal de Pernambuco

${ }^{3}$ Alex Sandro Gomes Universidade Federal de Pernambuco Recife - PE - Brasil

Recebido em 28/1/18 Aceito em 16/07/19

Abstract

The educational system in Brazil is undergoing a renewal process aimed at achieving international quality standards. This requires significant efforts to tackle the different problems public schools are faced with in Brazil, where physical infrastructure, human resources, pedagogical and digital resources should operate together. The modernisation of traditional educational strategies points to a tendency to implement a hybrid education system, through the insertion of Information and Communication Technologies (ICTs) This paper discusses the standard layouts of current learning environments and the development of new concepts, innovative building and technological aspects that may positively affect the ergonomic conditions of learning environments. This is a qualitative study, and the method adopted is based on a triangulation between Design Science Research and ergonomics methods to evaluate and design indoor school environments. The results point to the development of new spatial layouts for learning environments, with the application of flexibilities concepts for multiple learning activities, innovative formal solutions, ergonomic dimensional principles and technical specifications for spatial elements, systems and comfort conditions.

Keywords: Learning environment. Ergonomics specifications. Blended Learning.
\end{abstract}




\section{Introdução}

As discussões sobre inovação em ensino abordam novas metodologias, tecnologias de ensino e de aprendizagem e a redefinição dos papéis de professores e de estudantes, no sentido de uma educação centrada no estudante. Gomes e Silva (2016) e Sibilia (2012) afirmam que a maioria das escolas é projetada no formato cells-and-bells: estudantes ocupam células chamadas salas de aula até o sino tocar, e então eles mudam para outra célula. Esse modelo surgiu na era pós-revolução industrial, com o nascimento do Taylorismo, e propunha o fornecimento de conteúdos unicamente pelo professor, de modo pouco integrado, ou relativo aos problemas da vida cotidiana (GOMES; SILVA, 2016). É visível a necessidade de atualizar os ambientes de aprendizagem para que estejam compatíveis com os recursos tecnológicos atuais, mesmo em escolas que prezam pela inovação e que incorporam recursos digitais de aprendizagem.

As propostas de educação híbrida enfatizam a promoção da inserção de novas tecnologias em sala de aula (HUANG et al. 2012; BACICH; TANZI NETO; TREVISANI, 2015; HORN; STALKER, 2015). Entretanto, diante da enorme precariedade em infraestrutura escolar existente no Brasil, em que não há capacidade suficiente para uma ruptura brusca no sistema educacional, sugere-se aproveitar "o melhor dos dois mundos" (BACICH; TANZI NETO; TREVISANI, 2015, p. 53), referindo-se a incorporar estratégias de Tecnologias da Informação e Comunicação (TICs) ao ensino dito tradicional.

Blended learning, ou ensino híbrido, relaciona-se com a ideia de uma aprendizagem compartilhada, com amplo acesso à informação, em qualquer tempo, gerando uma mudança profunda nos papéis desempenhados pelos professores e estudantes, uma vez que o conhecimento pode ser produzido e compartilhado através das TICs. Modificam-se totalmente as relações de domínio do conhecimento em sala, e da mesma maneira a configuração dos ambientes de aprendizagem necessita ser revista e atualizada. Moran (2015) reforça que: "Agora, com a mobilidade e a conectividade, é muito mais perceptível, amplo e profundo: é um ecossistema mais aberto e criativo. Podemos ensinar e aprender de inúmeras formas, em todos os momentos, em múltiplos espaços." (MORAN, 2015, p. 23).

O estudo de Kaup, Kim e Dudek (2013), Chan e Richardson (2005) e Thapa et al. (2013) aponta para a relação entre o planejamento e o clima social de espaços de aprendizagem, quanto ao desempenho do estudante na escola e os impactos relativos à qualidade do edifícios e dos ambientes internos de aprendizagem, corroborando os estudos de Barrett et al. (2015), Bluyssen (2017), Heschong Mahone Group (2003), Tanner (2009), Powell (2015), Fraser (2015), Vasquéz, Pereira e Kuhnen (2018), Cornelius-White (2007) e Freiberg e Lamb (2009). Souza (2018) estudou as configurações espaciais para o ensino fundamental em São Paulo, relacionando as teorias da aprendizagem existentes e a influência delas à concepção de espaços escolares, e concorda com Taylor (2009) sobre a importância do estudo do espaço escolar associado ao sistema educacional, pois considera o espaço um participante ativo do currículo ou, ainda, um "terceiro professor", denominação também utilizada por Cannon Design vs Furniture e Bruce Mau Design (2010, p. 58).

$\mathrm{O}$ ambiente exerce influência nos estudantes, causando sensações positivas e, às vezes, negativas. Essas implicações são diferentes de pessoa para pessoa, mesmo assim percebe-se que há influência da qualidade do ambiente nas interações sociais que ocorrem no grupo ao qual pertencem (KAUP; KIM; DUDEK, 2013; CHAN; RICHARDSON, 2005). É fundamental considerar a importância do papel exercido pelo espaço físico e pelo clima social proporcionado pela escola no desempenho dos estudantes.

Os problemas que envolvem a estagnação dos atuais ambientes de aprendizagem no Brasil estão muitas vezes ligados à baixa qualidade dos processos de construção de escolas, especialmente nas cidades mais pobres do país. Apesar de investir cerca de 6\% do Produto Interno Bruto (PIB) em educação pública, porcentagem maior que muitos países ricos, o valor gasto por aluno no Brasil ainda é pequeno (ORGANIZATION..., 2018). O Censo Escolar 2017 (INSTITUTO..., 2018) apontou grandes problemas de infraestrutura em escolas de ensino fundamental no Brasil:

(a) apenas $41,6 \%$ das escolas contam com rede de esgoto;

(b) o fornecimento de água, por rede pública, ocorre em $65,8 \%$ das escolas;

(c) em $10 \%$ das escolas do país não há nenhum abastecimento de energia ou água;

(d) 46,8\% das escolas de ensino fundamental dispõem de laboratório de informática, 65,6\% das escolas têm acesso à internet; em 53,5\% das escolas a internet é por banda larga;

(e) apenas $11,5 \%$ das escolas de ensino fundamental dispõem de laboratório de ciências, 53,5\% das escolas dispõem de biblioteca e/ou sala de leitura; 
(f) ter banheiro acessível é uma realidade em apenas 39,9\% das escolas, e em 9,2\% das escolas não existe banheiro; e

(g) espaços de lazer e convivência foram observados nas seguintes proporções: $27,5 \%$ das escolas fundamentais e infantis dispõem de parque infantil, 67,5\% das escolas possuem pátio (coberto ou descoberto) e 41,2\% das escolas têm quadra de esportes.

Esses dados mostram que no Brasil há preocupação em prover condições mínimas de infraestrutura na rede pública de ensino, entretanto não há evidências da qualidade ou de padrões de conforto ou de eficiência dos ambientes de aprendizagem oferecidos. Os manuais da FDE preconizam recomendações e critérios mínimos para o dimensionamento de ambientes escolares e especificações técnicas de instalações e mobiliário básico, entretanto aspectos da acessibilidade e de conforto ergonômico e psicológico, que impactam na qualidade de edificações escolares, precisam ser mais bem estudados.

Diante dessa problemática, o presente artigo questiona a configuração e as especificidades dos padrões de espaços de aprendizagem tradicionais, que não são apropriados para atender às mudanças de paradigma educacional, visando a implantação de estratégias de educação híbrida. O produto do artigo envolve a elaboração de atualizações de arranjos espaciais e de especificações técnicas para ambientes de aprendizagem de escolas públicas voltados à educação enriquecida com novas tecnologias, no contexto da educação híbrida. A contribuição principal desta pesquisa atua no sentido de elaborar soluções espaciais através de uma metodologia multimétodo, que engloba estratégias de análise ergonômica e projeto de artefatos ambientais, utilizando ferramentas de design participativo.

\section{Referencial teórico}

Gomes e Silva (2016) apontam que a apropriação de tecnologias digitais na escola tem sido preconizada por gestores de escolas públicas e particulares há mais de duas décadas, no entanto com pouca efetividade. Essa falta de efetividade nos leva a pensar no contexto escolar sob uma égide tecnológica (digital), considerando as implicações da tecnologia sobre as práticas de ensino-aprendizagem.

Aprender e ensinar envolve selecionar as melhores informações, sistematizá-las e transformá-las em conhecimento, em um processo dialógico com os alunos, tirando o máximo proveito dos recursos disponíveis na escola. Tais recursos podem ser didáticos, formas de relacionamento interpessoal e também de acesso às melhores condições físicas para a realização das práticas de aprendizagem. Gerir recursos e elementos que compõem novas formas de ensinar e aprender são desafios aos professores no século XXI, isso inclui como utilizar recurso diversos, que possam dinamizar a apreensão do conteúdo.

O atual contexto cultural traz a imersão tecnológica como parte fundamental de um cenário, que se intitula cultura digital (GOMES et al., 2015), que já é percebido diariamente ao utilizarmos os recursos tecnológicos e digitais para facilitar as tarefas diárias. Do ponto de vista das mudanças na vida escolar, Sibilia (2012) e Gomes e Silva (2016) descrevem os conflitos resultantes da mudança de paradigma de uma escola construída e vivenciada como tradicional, que enfrenta um momento de transição para uma nova configuração invadida pela cultural digital.

Bowers (2010) afirma que o design da sala de aula é uma ferramenta de tecnologia. As configurações estáticas dos espaços físicos de educação limitam interações e práticas pedagógicas, especialmente práticas inovadoras, ligadas ao uso de recursos digitais e on-line. Para uma efetiva mudança de paradigma educacional é preciso reconfigurar o design das salas de aula (seus recursos e ambiente físico) para atender às mudanças progressivas que estão sendo empregadas do ensino tradicional para o ensino centrado no estudante, de acordo com os relatos de Cornell (2002), Freiberg e Lamb (2009), Rogers e Freiberg (1994), Nair (2014), Tibúrcio (2005, 2008), Kowaltoski (2011) Guidalli (2012) e Huang et al. (2012). No Quadro 1 a seguir resumem-se as intercessões das mudanças, como citado pelos autores acima mencionados.

Para entender como a tecnologia vem se inserindo nos processos de ensino-aprendizagem, Kim e Hannafin (2011) estudaram os benefícios notados por alunos e professores. Carle, Jaffee e Miller (2009), Mann (2008) demonstraram que investimentos realizados têm sido voltados à aquisição de tecnologias como estratégia para melhorar a aprendizagem. 
Quadro 1 - Resumo das características de mudanças no sistema educacional, desde o ensino tradicional para o ensino centrado no estudante

\begin{tabular}{|c|c|c|}
\hline Ensino tradicional & $\begin{array}{l}\text { Melhorias no design de } \\
\text { ambientes de aprendizagem }\end{array}$ & Ensino centrado no estudante \\
\hline Professor é o único líder & Salas mais amplas e flexíveis & Liderança compartilhada \\
\hline $\begin{array}{l}\text { Gerenciamento é uma forma de } \\
\text { controle }\end{array}$ & $\begin{array}{l}\text { Maior dimensionamento interno } \\
\text { permitindo flexibilização do } \\
\text { leiaute }\end{array}$ & Gerenciamento é forma de guia \\
\hline $\begin{array}{c}\text { Professor é responsável por } \\
\text { todos os trabalhos e sua } \\
\text { organização } \\
\end{array}$ & $\begin{array}{c}\text { Mobiliário leve e variado para } \\
\text { atender as atividades de } \\
\text { aprendizagem } \\
\end{array}$ & $\begin{array}{l}\text { Estudantes organizam os } \\
\text { trabalhos coletivamente }\end{array}$ \\
\hline $\begin{array}{l}\text { Disciplina é imposta pelo } \\
\text { professor }\end{array}$ & $\begin{array}{c}\text { Recursos tecnológicos, digitais e } \\
\text { rede disponíveis a qualquer } \\
\text { tempo }\end{array}$ & $\begin{array}{l}\text { Disciplina evolui de cada } \\
\text { indivíduo }\end{array}$ \\
\hline $\begin{array}{l}\text { Poucos estudantes ajudam o } \\
\text { professor }\end{array}$ & $\begin{array}{c}\text { Variações de arranjos e de } \\
\text { leiaute }\end{array}$ & Todos podem participar \\
\hline $\begin{array}{c}\text { Professor gera as regras e impõe } \\
\text { aos estudantes }\end{array}$ & $\begin{array}{c}\text { Equipamentos e mídias } \\
\text { funcionando a qualquer tempo }\end{array}$ & $\begin{array}{c}\text { Regras são acordos estabelecidos } \\
\text { por todos } \\
\end{array}$ \\
\hline $\begin{array}{l}\text { Consequências são fixadas a } \\
\text { todos }\end{array}$ & $\begin{array}{c}\text { Professores e estudantes } \\
\text { dominando os recursos digitais } \\
\text { plenamente }\end{array}$ & $\begin{array}{l}\text { Consequências são reflexos das } \\
\text { diferenças individuais }\end{array}$ \\
\hline $\begin{array}{c}\text { Reconhecimento do progresso é } \\
\text { em maioria extrínseco }\end{array}$ & $\begin{array}{c}\text { Transparências para visualização } \\
\text { interior/exterior }\end{array}$ & $\begin{array}{c}\text { Reconhecimento do progresso é } \\
\text { em maioria intrínseco }\end{array}$ \\
\hline $\begin{array}{l}\text { Estudantes são permitidos } \\
\text { responsabilidades limitadas }\end{array}$ & $\begin{array}{c}\text { Espaços atraentes e confortáveis } \\
\text { para ler, conversar, trabalhar e } \\
\text { descansar } \\
\end{array}$ & $\begin{array}{c}\text { Estudantes compartilham as } \\
\text { responsabilidades dos recursos e } \\
\text { do espaço da aula } \\
\end{array}$ \\
\hline $\begin{array}{l}\text { Poucos membros da comunidade } \\
\text { participam das aulas }\end{array}$ & $\begin{array}{l}\text { Interatividade, acessibilidade e } \\
\text { personalização }\end{array}$ & $\begin{array}{c}\text { Parcerias externas à escola } \\
\text { enriquecem as práticas } \\
\text { educativas }\end{array}$ \\
\hline Avaliações individuais & $\begin{array}{c}\text { Acesso convidativo, ambiente } \\
\text { acolhedor e jovial }\end{array}$ & Variadas formas de avaliações \\
\hline $\begin{array}{l}\text { Aprendizagem linear baseada em } \\
\text { conteúdo expositivo }\end{array}$ & $\begin{array}{c}\text { Espaços adicionais para descanso } \\
\text { e convivência }\end{array}$ & $\begin{array}{l}\text { Aprendizagens múltiplas } \\
\text { baseadas em processos }\end{array}$ \\
\hline
\end{tabular}

Fonte: baseados em Cornell (2002), Freiberg e Lamb (2009), Rogers e Freiberg (1994), Nair (2014), Tibúrcio (2005,

2008), Kowaltoski (2011), Guidalli (2012) e Huang et al. (2012).

Embora o pensamento dos órgãos gestores no Brasil seja de que a infraestrutura nas escolas vem melhorando, no sentido da oferta de equipamentos que facilitam a aprendizagem, a distribuição dessa infraestrutura em escolas brasileiras ainda é bastante desigual (INSTITUTO..., 2018) e concentrada nas redes escolares privadas, especialmente em grandes cidades. Talvez por esse motivo a mudança de paradigma não é completa e a maioria dos professores só usa a tecnologia para projetar materiais instrucionais (HERMANS et al., 2008) ou ministrar palestras. Utiliza-se a tecnologia de maneira pouco produtiva e de forma reduzida, concordando com Yen e Lee (2011), que permanecem a utilizá-la de maneira experimental.

Quanto ao ambiente físico de ensino tradicional, onde se realizam as atividades didáticas, percebe-se que os problemas da falta de planejamento espacial são agravados ao verificar-se as condições de inadequação ergonômica do mobiliário, a má iluminação em mesas de trabalho, o mau posicionamento das telas dos desktops em relação à lousa e em relação às janelas, a pouca proteção das aberturas contra o ofuscamento, causado pela iluminação direta. Somam-se a esses problemas turmas muito numerosas e um único professor para conduzir a aprendizagem. Destaca-se a má iluminação (natural e artificial) e a pouca flexibilidade das salas de aula como fator de grande impacto no progresso da aprendizagem das crianças (BARRETT et al., 2015). Nota-se que são precariamente seguidas as condições mínimas de conforto ambiental em salas de aula, de acordo com Kowaltowski (2011), Guindalli e Bins Ely (2013), Bertolotti (2007), Alcântara (2011), que recomendam os seguintes critérios de desempenho: 
(a) desempenho térmico proporcionado por sombreamento de aberturas (cortinas, persianas, brises externos, entorno e vegetação), uso de ventilação natural, cruzada ou mecânica (KOWALTOWSKI, 2011); seguir a NBR 15220 (ABNT, 2003) para obter sombreamento de aberturas respeitando as recomendações para as zonas bioclimáticas brasileiras: Zona 1 - permitir entrada de sol no período frio, Zonas 2 e 3 permitir entrada de sol no inverno, e Zonas 4 a 8 - sombrear aberturas durante todo o ano (GURGEL, 2012; ABNT, 2003);

(b) aplicar as recomendações mínimas de desempenho para cada aspecto de conforto ambiental — térmico (NBR 15220, ABNT, 2003), lumínico (ABNT, 2013) e acústico (ABNT, 1999), criando assim uma base mínima de níveis de conforto; e

(c) iluminação natural uniforme, indireta e refletida sobre o plano de trabalho, prevendo uma faixa contínua de janelas e prateleiras de luz (GUINDALLI; BINS ELY, 2013; BERTOLOTTI, 2007; HESCHONG; MAHONE, 1999).

(d) Boa condição acústica para a palavra falada, níveis baixos de ruído de fundo, não interferindo na inteligibilidade, salas livres de eco ou de fenômenos de distorção sonora, devendo propiciar o tempo de reverberação adequado para cada tipo de atividade (ALCÂNTARA, 2011).

Do ponto de vista das análises históricas e tipológicas, destacam-se os estudos de Souza (2018), que realizou uma análise dos padrões tipológicos de edificações escolares no Brasil, dos séculos XXI e XX em São Paulo, e mesmo sentido; e os estudo de Santiago (2017), que realizou uma análise dos padrões tipológicos escolares no Estado do Ceará, para os séculos XIX e XX, ambos os trabalhos abordaram a unidade da edificação escolar como um todo. Apesar de a edificação escolar influenciar o bem-estar dos usuários e as condições efetivas da aprendizagem, de maneira global, esta pesquisa se deteve a analisar os aspectos dos leiautes dos ambientes de aprendizagem formais, os padrões de salas de aula e seus elementos definidores.

Apesar das diretrizes de conforto e das inúmeras pesquisas que abordam o desempenho ambiental de ambientes escolares, a configuração dos leiautes de ambientes de aprendizagem ainda é pouco estudada no Brasil. Leiautes flexíveis implicariam maior variedade de situações para a realização de atividades múltiplas de aprendizagem (NAIR; FIELDING; LACKNEY, 2013) adequadas ao ensino centrado no estudante e adoção de novas tecnologias. Desse modo, apresentam-se as contradições entre os padrões estabelecidos para leiautes de ambientes de aprendizagem no Brasil ao longo dos últimos 20 anos e as inovações encontradas em outros países, simultaneamente para o mesmo período.

\section{Padrões de leiautes de ambientes de aprendizagem no Brasil (1990 a 2017)}

As configurações dimensionais e de uso de salas de aula de ensino fundamental que são seguidos em todo o país são: carteiras são ordenadas em fileira, podendo agrupar-se em duplas, de até 36 estudantes, numa área útil de 51,84 m² (FUNDAÇÃO..., 2017; FUNDESCOLA, 1999). Os três leiautes apresentados foram elaborados em um intervalo de 17 anos (1999 a 2016) pela Fundescola/MEC (1999 e 2002) e FDE (FUNDAÇÃO..., 2017), tempo em que mudanças tecnológicas implicaram em uma reconfiguração global de formas de aprendizagem. Entretanto, não se percebem mudanças significativas nos leiautes propostos. As únicas alterações visíveis, conforme a Figura 1a, são a inclusão de uma vaga reservada à pessoa com deficiência, equipamentos de projeção para atividade expositiva, e nas especificações nota-se a inclusão de novos pontos de energia, distribuídos no ambiente. A relação área útil/pessoa fica estabelecida de 1,44 $\mathrm{m}^{2}$ /pessoa. No Brasil, as portas de salas de aula ainda não se adequam às recomendações e normas de segurança do corpo de bombeiros, abrindo para fora do ambiente, em direção ao fluxo de fuga.

O MEC definiu padrões dimensionais de referência para todo o Brasil ainda menores que os definidos pela FDE: área útil: 41,31 m² (1,15 m²/estudante) para a mesma capacidade de turma - 36 estudantes. O mobiliário básico fora: lousa de giz, mesas e cadeiras fixas, armários em aço e iluminação fluorescente (FUNDESCOLA, 1999, 2002). Para atividades de uso múltiplo, de caráter prático, ou interativo, a FDE apontou o leiaute da Figura 2 como sugestão de arranjo. A área útil dimensionada foi de 51,84 $\mathrm{m}^{2}$. Não se percebe uma grande alteração de leiaute, apenas o acréscimo, a partir de 2015, de uma antessala de preparo (Figura 2c), de um espaço pré-definido para pessoa com deficiência (em azul na Figura 2c), e de equipamentos de projeção. Para atividades de uso múltiplo, conforme a Figura 2c, o MEC recomenda um leiaute desenvolvido pela Fundescola (2002). As recomendações dimensionais foram: área útil de 59,93 $\mathrm{m}^{2}$, para uma turma de 18 estudantes, sendo a relação área útil/estudante de 3,33 $\mathrm{m}^{2} /$ pessoa.

Com a chegada de ferramentas computacionais nas escolas, foram criadas salas de informática. O primeiro arranjo proposto pela Fundescola (2002) previu a acomodação de computadores de mesa e periféricos, 
conforme a Figura 3a. Mais recentemente, a FDE (FUNDAÇÃO..., 2017) elaborou um leiaute de sala de informática (Figura 3b). Os dados dimensionais do leiaute elaborado pela Fundescola (2002) são: área útil de $52,87 \mathrm{~m}^{2}$, para uma turma de 18 estudantes, perfazendo uma relação de 2,94 $\mathrm{m}^{2} /$ estudante, e os dados dimensionais do leiaute da FDE são: área útil $51,84 \mathrm{~m}^{2}$, para uma turma de 18 estudantes, perfazendo uma relação de 2,88 $\mathrm{m}^{2} /$ estudante.

Percebe-se no leiaute da FDE (DUNDAÇÃO..., 2017) uma mudança no arranjo, podendo causar desconforto postural ao sugerir que o estudante permaneça de costas para a lousa, situação que dificulta a atenção na discussão do conteúdo, e, assim, força o estudante a realizar movimentos de rotação frequentes de pescoço e costas, situação ergonomicamente desfavorável. Uma abordagem ergonômica mais adequada sugere o uso de cadeiras giratórias, permitindo maior flexibilidade ao usuário.

Em ambientes para informática, aponta-se para os seguintes tipos de mobiliário: mesas individuais ou coletivas; suportes de comunicação: quadros de giz, quadros para canetas e quadro-mural; móveis para: guarda de utensílios, material em uso e trabalhos concluídos; suporte de máquinas ou aparelhos de utilização comum como televisores, vídeos, projetores e outros equipamentos. A FDE (FUNDAÇÃO..., 2017) incorporou a especificação de cadeiras giratórias, sem apoio de braços, também considerada desconfortável do ponto de vista ergonômico.

Figura 1 - Leiautes de salas de aula proposto pela FDE e pela Fundescola

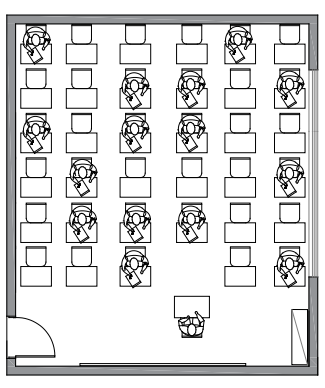

FUNDESCOLA (1990)

(a)

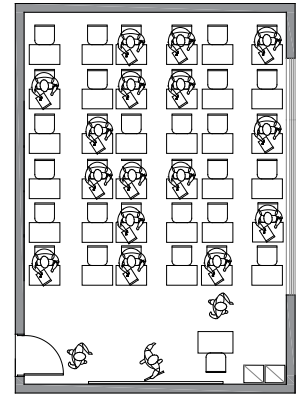

FUNDESCOLA (2002)

(b)

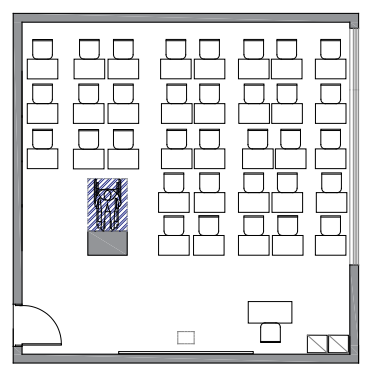

FDE (2017)

(c)

Fonte: baseado em: (a) Fundescola (2009), (b) Fundescola (2002) e (c) FDE (FUNDAÇÃO..., 2017).

Figura 2 - Leiautes de sala de aula de uso múltiplo, para realização de trabalhos práticos ou coletivos

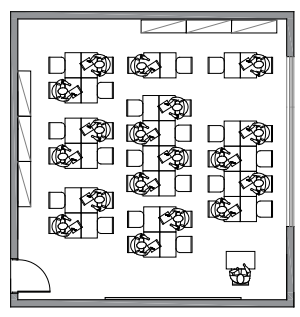

FUNDESCOLA (1990)

(a)

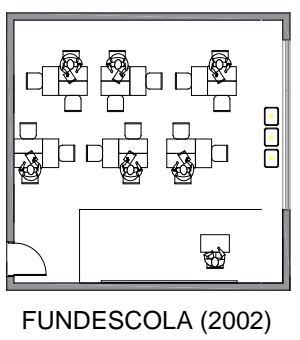

(b)

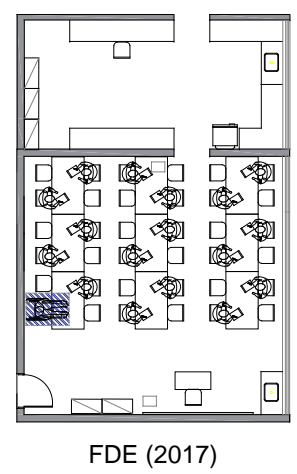

(c)

Fonte: baseado em: (a) Fundescola (2009), (b) Fundescola (2002) e (c) FDE (FUNDAÇÃO..., 2017). 
Figura 3 - Leiautes para salas de informática

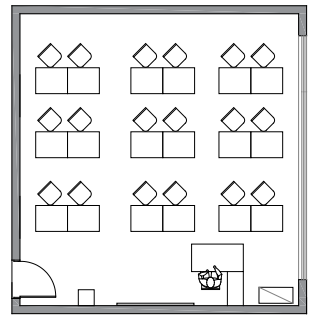

FUNDESCOLA (2002)

(a)

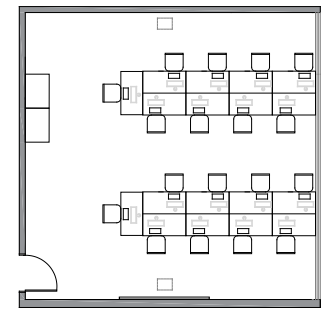

FDE (2017)

(b)

Fonte: baseado em: (a) Fundescola (2009), (b) Fundescola (2002) e (c) FDE (FUNDAÇÃO..., 2017).

A Tabela 1, a seguir, demonstra a comparação entre as recomendações dimensionais apontadas pela Fundescola/MEC (FUNDESCOLA..., 2002) e FDE (FUNDAÇÃO..., 2017) para os principais ambientes de aprendizagem em escolas brasileiras e referências encontradas na literatura, de acordo com Neufert (2013), ASU (ARIZONA..., 2013) e NYSDH (NEW YORK..., 2010). Percebe-se que não houve uma melhora real na relação área útil/estudantes para os ambientes de aprendizagem nas escolas brasileiras no período observado entre as duas principais publicações (FUNDESCOLA, 2002; FUNDAÇÃO..., 2017) e nota-se que os padrões de dimensionamento para infraestrutura do ambiente construído são insatisfatórios e engessados. A relação área/estudante é melhor nas referências internacionais (1,57 a $2 \mathrm{~m}^{2} /$ estudante), exceto para a sala de uso múltiplo em 2002 (3,33 m²/estudante), de acordo com Fundescola (2002), entretanto esse índice foi bastante reduzido (1,44 m²/estudante) pela FDE (FUNDAÇÃO..., 2017). Em salas de informática, os índices de área/estudante estão compatíveis com referências internacionais.

Kowaltoski, Deliberador e Pereira (2013) estudaram os processos de projeto de edificações escolares realizados pela FDE no Brasil, realizando entrevistas com cerca de 44 arquitetos ligados à instituição. As autoras concluíram que nos processos de projetos escolares raramente são utilizadas informações recentes advindas da literatura especializada em edificação escolar, resultando em projetos simplificados em relação ao atendimento de normas e recomendações nacionais e internacionais. O espaço da sala de aula não foi mencionado como objeto de atenção especial durante o processo de projeto (menos de $5 \%$ dos entrevistados mencionaram esse critério). Foi demonstrada pouca liberdade de discussão, ou pouco interesse em melhorar as salas de aula. Os critérios de projeto mais destacados pelos arquitetos foram iluminação natural (40\% dos entrevistados), ventilação natural e assinatura local (cerca de 30\% dos entrevistados), orientação da edificação e sombreamento de aberturas também foram mencionados em menor proporção.

Soma-se a isso o fato de que na maioria das escolas públicas, a compra de bens, contratações de serviços e de obras, utiliza-se o Sistema de Registros de Preços (SPP), regido pela Lei Federal n. 8.666, de 1993 (PRESIDÊNCIA..., 1993), que estabelece que "a licitação para registro de preços será realizada na modalidade de concorrência, do tipo menor preço" (PRESIDÊNCIA...., 2013). Esse critério muitas vezes sobrepõe-se a especificações relativas à qualidade dos produtos e dos serviços, como, por exemplo, dificultando a compra de bens mais duráveis, ou mais confortáveis, como poltronas de leitura, mesas com rodízios ou com encaixes para atividades em grupo; também afeta a execução de obras escolares que poderiam estar direcionadas a tornar os ambientes de aprendizagem mais acolhedores, generosos e flexíveis, resultando na percepção de que a escola seria o local de inovação, de identidade social e de aprendizagem colaborativa, indo além do atendimento de critérios mínimos dimensionais ou normativos.

A flexibilidade no uso do espaço que poderia ser um critério projetual primário, previsto ainda na fase de elaboração do programa de necessidades, exigiria apenas um pequeno aumento de área útil, para uma melhora considerável na condição de conforto e bem-estar dos usuários, é na verdade não considerada em projetos de edificações públicas escolares no Brasil.

Nos últimos 30 anos a configuração arquitetônica mais usada em edifícios escolares remete a um formato monolítico padronizado de até 3 pavimentos. Souza (2018) e Santiago (2017) demonstraram que a tipologia escolar segue uma organização espacial em pavimentos; organizadas em corredores lineares, as salas de aula são retangulares ou quadradas. Os formatos de corredores mais frequentes são em linha, em U ou em L. Recentemente foram incorporados a quadra de esportes (de maneira a não causar interferências acústicas em salas de aula), o refeitório e as salas de informática, confirmando os dados do Censo Escolar 2017 (INEP, 2018) de que esses ambientes ainda não estão presentes na maioria das escolas públicas brasileiras. 
Tabela 1 - Comparativo entre as recomendações dimensionais para ambientes de sala de aula

\begin{tabular}{|c|c|c|c|c|c|}
\hline $\begin{array}{c}\text { ESPECIFICAÇÕES SALAS } \\
\text { DE AULA }\end{array}$ & $\begin{array}{l}\text { Fundescola } \\
\text { (2002) }\end{array}$ & $\begin{array}{c}\text { FDE } \\
\text { (FUN- } \\
\text { DAÇÃO } \\
\text {..., 2017) }\end{array}$ & $\begin{array}{l}\text { Neufert } \\
\text { (2013) }\end{array}$ & \begin{tabular}{|c|} 
ASU \\
(ARI- \\
ZONA.... \\
2013) \\
\end{tabular} & $\begin{array}{c}\text { NYSDH } \\
\text { (NEW } \\
\text { YORK...., } \\
\text { 2010) } \\
\end{array}$ \\
\hline SALA CONVENCIONAL & - & - & - & - & - \\
\hline Área útil $\left(\mathbf{m}^{2}\right)$ & 41,31 & 51,84 & 54,00 & $>45$ & - \\
\hline $\begin{array}{l}\text { Relação área/estudante } \\
\left(\mathrm{m}^{2} / \text { pessoa) }\right.\end{array}$ & 1,15 & 1,44 & $>1,5$ & $1,8-2$ & $1,57-2$ \\
\hline $\begin{array}{l}\text { Lotação máxima da turma (no } \\
\text { de estudantes) }\end{array}$ & 36 & 36 & 45 & $25-60$ & 41 \\
\hline SALA DE USO MÚLTIPLO & - & - & - & - & - \\
\hline Área útil $\left(\mathbf{m}^{2}\right)$ & 59,93 & 51,84 & $36-60$ & $>58$ & - \\
\hline $\begin{array}{l}\text { Relação área/estudante } \\
\left(\mathrm{m}^{2} / \text { pessoa) }\right.\end{array}$ & 3,33 & 1,44 & 2,25 & 2,32 & 2,32 \\
\hline $\begin{array}{l}\text { Lotação máxima da turma (n } \\
\text { de estudantes) }\end{array}$ & 18 & 36 & $16-25$ & $<40$ & $20-40$ \\
\hline SALA DE INFORMÁTICA & - & - & - & - & - \\
\hline Área útil (m²) & 52,87 & 51,84 & - & - & - \\
\hline $\begin{array}{l}\text { Relação área/estudante } \\
\text { (m²/pessoa) }\end{array}$ & 2,94 & 2,88 & - & 2,97 & $2,7-3,7$ \\
\hline $\begin{array}{l}\text { Lotação máxima da turma (no } \\
\text { de estudantes) }\end{array}$ & 18 & 18 & - & - & - \\
\hline
\end{tabular}

Fonte: adaptado de FDE (FUNDAÇÃO..., 2017), Fundescola (2002), Neufert (2013), ASU (ARIZONA..., 2013) e NYSDH (NEW YORK..., 2010).

Mesmo em projetos contemporâneos nos quais se nota um maior cuidado com aspectos estéticos e de eficiência energética da edificação escolar, nos ambientes internos, de maior permanência, não houve mudanças significativas de leiaute. Para atender a tendência de uma aprendizagem baseada em atividades múltiplas, a área mínima (por aluno) recomendada não prevê espaços adequados para armazenamento de materiais pessoais dos estudantes, armários e estantes dentro das salas, muito menos fora das salas recomendam-se critérios para espaços de convivência, de leitura ou de aprendizagem colaborativa, mesmo considerando que as especificações técnicas e de instalações prediais foram mais bem detalhadas nas recentes publicações da FDE (FUNDAÇÃO..., 2017).

\section{Inovações em ambientes de aprendizagem (1940-2017)}

Nair, Fielding e Lackney (2013) relatam experiências com salas de aula em um formato em L — learning studio, criado em 1940 e definido por uma área ativa (entrada, armários, área de trabalho), um espaço central flexível (para seminários, estudo individual, estudo colaborativo e apresentações) e área de descanso (com assentos macios) na lateral. É uma sala de aula redesenhada conscientemente para aumentar o número de modalidades de aprendizagem, permitindo mais atividades do que em salas tradicionais. Kowaltoski, Deliberador e Pereira (2013) destacam o formato da sala em Z — Z-shaped classroom, estudado por Nies e Hougsted (1997), especialmente adequado aos anos iniciais do ensino fundamental.

Thornburg (1999) definiu que um espaço de aprendizagem deve permitir aos estudantes experimentar 4 abrangentes modos de aprender: CAMPFIRE (aprendizagem com um especialista); WATERING HOLE (aprendizagem com os pares); CAVE (aprendizagem por introspecção — estudo individual); LIFE (aprender fazendo). Das iniciativas inovadoras posteriores, muitas convergem para esses parâmetros, permitindo aos usuários desfrutar de mais conforto e flexibilização para atividades de aprendizagem. Destacam-se:

(a) Learning suites (dois ou mais learning studios combinados), local de trabalho totalmente colaborativo, juntando até 4 turmas em um único espaço multidisciplinar sob orientação de até 4 professores (NAIR; FIELDING; LACKNEY, 2013);

(b) Engaged Learning Model, em que o professor deixa de ser o "sábio ao palco" para se tornar o "guia ao lado”. O mobiliário é flexível, permitindo as dinâmicas e o aumento de oportunidades para os diferentes tipos de aprendizes (CANNON DESIGN..., 2010); 
(c) Vittra School - formatos de aprendizagem, baseados na utilização das tecnologias digitais e em experiências de ensino híbrido. Baseia-se em aprender com base em suas necessidades, curiosidades e inclinações, aumentar a motivação e a inspiração, compreender a aprendizagem, preparar o indivíduo para o estudo e o trabalho em um ambiente internacional e multicultural (ARCHDAILY.COM, 2012).

(d) Smart Classroom - proposta de configuração ótima para conteúdos expositivos, acesso livre a recursos de aprendizagem digital e interatividade promovidos pelo uso contínuo de TICs (HUANG et al., 2012); e

(e) O leiaute para ambiente de aprendizagem desenvolvido pelo Centre of Initiative in the Excellence of Teaching and Learning (CETL) das universidades de Sussex e Brighton no Reino Unido.

Destacam-se propostas inovadoras no Brasil, mesmo dentro de orçamentos reduzidos e diretrizes bastante rígidas. Exemplos de edificações escolares públicas inovadoras, nas quais o projeto pedagógico está conectado com espaços de aprendizagem não convencionais são: Escola Técnica Cícero Dias, em Recife, PE, e o Colégio Estadual José Leite Lopes, no Rio de Janeiro, RJ (escolas de ensino médio mantidas pelo programa Oi Futuro), e o projeto da Escola Casa Fundamental (ensino infantil e fundamental), em Belo Horizonte, MG.

Comparando-se as abordagens deste artigo com a revisão de literatura sobre aspectos espaciais de escolas no Brasil e no exterior, para o mesmo recorte temporal, percebem-se direcionamentos tecnológicos diferentes, dada a configuração do espaço escolar no Brasil, fato que justifica estudos que impliquem melhorias nas condições de espaços de aprendizagem no país, especialmente para escolas públicas, de forma a oferecer ambientes suficientemente flexíveis para abrigar múltiplas atividades de aprendizagem, incluindo aulas expositivas, atividades colaborativas, de laboratório, com uso irrestrito de recursos digitais.

\section{Método de pesquisa}

O método utilizado nesta pesquisa foi baseado no paradigma Design Science Research (DSR) (DRESCH; LACERDA; ANTUNES JUNIOR, 2015) e em métodos ergonômicos de avaliação e projeto do ambiente construído, para gerar um modelo de ambiente de aprendizagem adequado a práticas educativas do tipo blended learning. Esta triangulação metodológica resultou na aplicação de técnicas de pesquisa em 3 etapas: etapa observacional, desenvolvimento do artefato e avaliação do artefato. Os métodos ergonômicos utilizados foram: a metodologia ergonômica para o ambiente construído (MEAC) (VILLAROUCO, 2009) — para coleta e análise de dados nas escolas objetos do estudo, e as etapas de projetação ergonômicas desenvolvidas por Attaianese e Duca (2012) — para elaboração de propostas de novos arranjos espaciais de acordo com as atividades de aprendizagem relacionadas com blended learning. As amostras populacionais foram divididas em grupos de estudantes, professores e especialistas (arquitetos, designers e engenheiros), que contribuíram na aplicação das 3 etapas da pesquisa, de modos distintos, que são detalhados a seguir.

\section{Etapa observacional}

Para compreender os contextos sociais e culturais dos usuários dos ambientes de aprendizagem existentes, foi executada uma pesquisa de campo, de abordagem etnográfica, em escolas de ensino médio em Recife, PE, envolvendo uma amostra de 45 estudantes e 3 professores. Para compreender o contexto espacial, em que são realizadas as atividades de aprendizagem, foram realizadas análises ergonômicas em 2 tipos de salas de aula — teórica e sala de informática, baseadas na MEAC (VILLAROUCO, 2009), conforme sequência descrita no Quadro 2. O objetivo desta etapa foi de compreender como os usuários lidam com tecnologia, como se relacionam com o ambiente de aprendizagem, como percebem o uso de metodologias educacionais ativas e de que maneira estas influenciam na eficiência do ambiente de aprendizagem, além de elencar e analisar as atividades desenvolvidas no ambiente construído.

\section{Desenvolvimento do artefato}

Considerando que o desenvolvimento do artefato é o objetivo do design science research, e esta pesquisa considerou questões ergonômicas dos ambientes de aprendizagem, após a etapa observacional partiu-se para a etapa prescritiva. Esta etapa é focada na solução espacial — elaboração de leiautes e especificações técnicas para ambientes de aprendizagem adequados a práticas de educação híbrida. Foram utilizadas técnicas de design briefing, workshop de design participativo (com usuários), síntese de requisitos ambientais e ergonômicos, ideação e concepção, projeto e prototipagem do artefato. Participaram 45 estudantes e 3 professores das etapas de desenvolvimento do artefato. Os resultados obtidos constam no Quadro 3. 


\section{Avaliação do artefato}

A avaliação das propostas foi majoritariamente qualitativa, e contou com uma etapa de avaliação quantitativa, para avaliar a satisfação dos especialistas. Em ambas as etapas, os avaliadores interagiram livremente com o artefato, através de um protótipo em realidade virtual. O protótipo foi apresentado em vídeo e em áudio descrição, descrevendo e demonstrando aspectos técnicos do artefato.

Numa primeira rodada de avaliações, as soluções espaciais foram expostas aos usuários usando realidade virtual, em sessões de grupos focais diferenciados por tipo de usuário — o primeiro grupo com 8 estudantes (originários de escolas diferentes) e o segundo grupo com 6 professores (originários de escolas diferentes). Após as interações, os avaliadores discutiram livremente suas opiniões sobre as propostas de leiautes apresentadas, e de modo espontâneo, as falas apontaram para comparações das propostas com as suas realidades vivenciadas em salas de aula tradicionais. Os dados obtidos com os relatos foram gravados e analisados para fins de realização de ajustes projetuais no artefato. Durante as discussões nos grupos focais, ficou claro que os usuários se remeteram às suas vivências nos ambientes de aprendizagem reais e de maneira comparativa, efetuaram observações com o artefato apresentado.

A segunda rodada de avaliações foi aplicada a 51 especialistas (arquitetos e designers) e ocorreu de modo quantitativo e individualizado, por meio de questionário calibrado, de aplicação on-line. Após a interação imersiva com as propostas em realidade virtual (de tempo livre), os avaliadores responderam a um questionário para mensurar a sua satisfação em relação a aspectos técnicos dos arranjos propostos. Os aspectos técnicos avaliados foram: soluções de leiaute versus flexibilidade, dimensionamento e acessibilidade do espaço de trabalho do professor, uso de cores e de materiais de revestimento, recursos tecnológicos e de infraestrutura, acomodação individual e guarda de pertences pessoais, especificações de conforto acústico, térmico e lumínico, forma espacial, conforto individual e acessibilidade de espaços secundários de estudo e posicionamento de aberturas.

Quadro 2 - Esquema das técnicas e resultados obtidos com a etapa observacional

\begin{tabular}{|l|l|}
\hline \multicolumn{1}{|c|}{ ETAPA } & \multicolumn{1}{c|}{ RESULTADOS OBTIDOS } \\
\hline Observação etnográfica & $\begin{array}{l}\text { Observação e análise dos padrões da atividade de } \\
\text { aprendizagem nos ambientes das escolas analisadas }\end{array}$ \\
\hline Entrevistas semiestruturadas ${ }^{1}$ & $\begin{array}{l}\text { Obtenção de dados sobre como os usuários lidam com as } \\
\text { TICs, e o impacto do uso delas nos ambientes de } \\
\text { aprendizagem }\end{array}$ \\
\hline Questionário on-line & $\begin{array}{l}\text { Caracterização do perfil sociocultural dos estudantes e as } \\
\text { preferências sobre os ambientes escolares que utilizam }\end{array}$ \\
\hline $\begin{array}{l}\text { Identificação da configuração } \\
\text { ambiental (VILLAROUCO, 2009) }\end{array}$ & $\begin{array}{l}\text { Obtenção de dados físico-espaciais e aferição de condições } \\
\text { de conforto - acústico, lumínico e térmico }\end{array}$ \\
\hline $\begin{array}{l}\text { Análise do ambiente em uso e Análise } \\
\text { da tarefa (VILLAROUCO, 2009; } \\
\text { ATTAIANESE; DUCA, 2012) }\end{array}$ & $\begin{array}{l}\text { Análise ergonômica dos usuários desenvolvendo tarefas nos } \\
\text { ambientes - posicionamentos, fluxos, circulações e } \\
\text { adequação ao mobiliário escolar. }\end{array}$ \\
\hline Análise da percepção do usuário & $\begin{array}{l}\text { Análise da satisfação dos usuários sobre os ambientes que } \\
\text { utilizam, por meio da aplicação de poema dos desejos } \\
\text { (SANOFF, 2001). }\end{array}$ \\
\hline
\end{tabular}

${ }^{1} \mathrm{~A}$ pesquisa e seus respectivos instrumentos foram aprovados pelo Comitê de Ética da UFPE e da Plataforma Brasil, sob o n. 2.055 .865 , em 10 de maio de 2017. 
Quadro 3 - Esquema de técnicas e resultados obtidos com o desenvolvimento do artefato (Continua...)

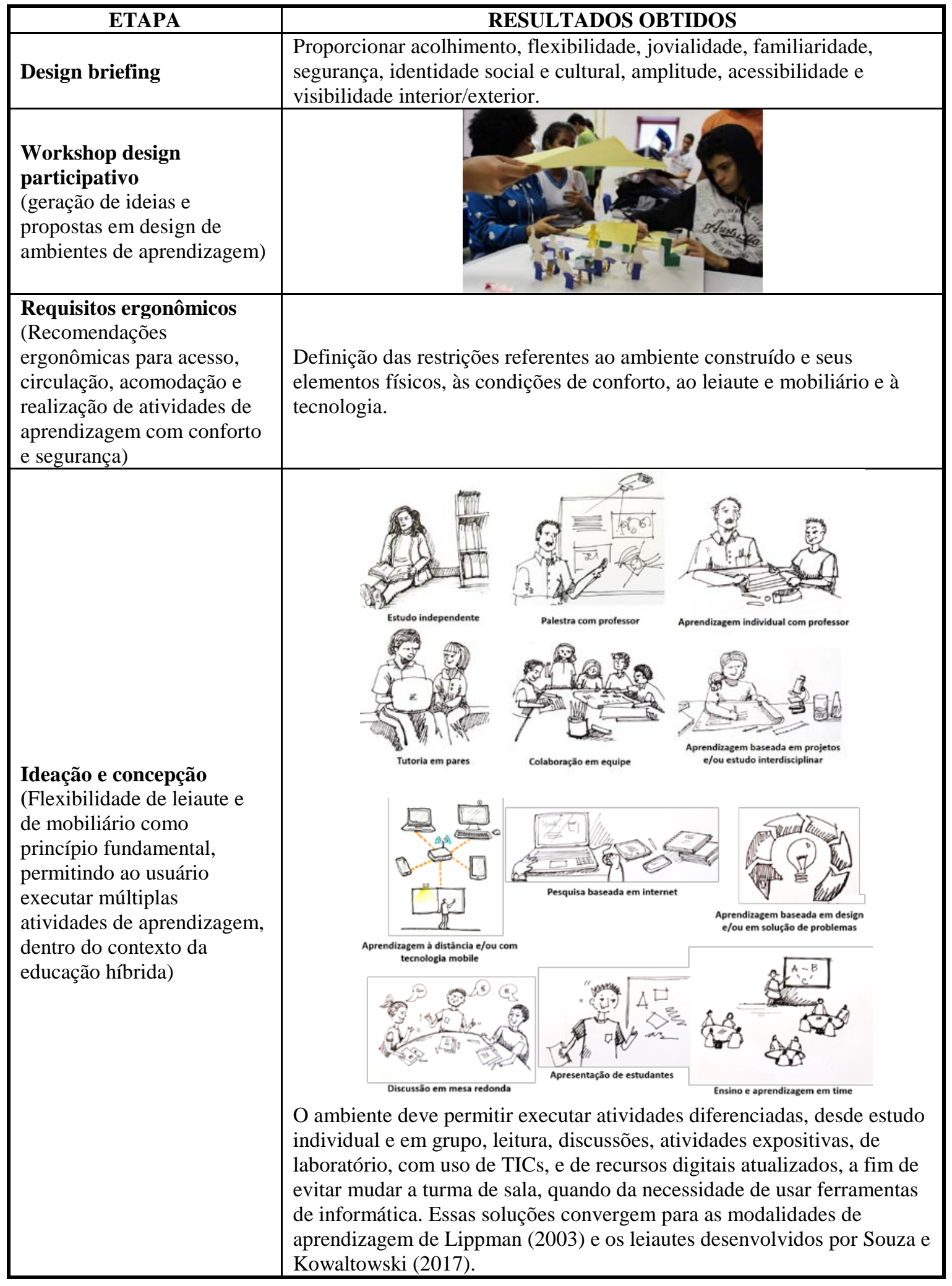




\section{Quadro 3 - Esquema de técnicas e resultados obtidos com o desenvolvimento do artefato (continuação)}

\begin{tabular}{ll|l|l|l|}
\hline $\begin{array}{l}\text { Projeto e prototipagem } \\
\text { (baseado em múltiplas } \\
\text { atividades e na acomodação } \\
\text { ergonômica dos usuários) }\end{array}$ \\
$\begin{array}{l}\text { Foi apresentado um ambiente de aprendizagem, que permite } 4 \text { rearranjos } \\
\text { espaciais, para adequar o ambiente às diferentes atividades de } \\
\text { aprendizagem - atividade expositiva, atividade em grupo, atividade de } \\
\text { laboratório com mesas individuais, palestras, discussões coletivas, estudo } \\
\text { individual, atividades externas etc. Internamente, a forma espacial } \\
\text { priorizou o não paralelismo das paredes (mesmo partindo do conjunto de } \\
\text { 2 salas retangulares), para proporcionar uma conformação mais dinâmica, } \\
\text { onde o centro do ambiente possa ser flexível às mudanças e estar voltado } \\
\text { às múltiplas atividades de aprendizagem. }\end{array}$ \\
\hline
\end{tabular}

\section{Resultados e discussões}

As respostas sobre o nível de satisfação com os aspectos analisados foram marcadas em uma escala de valoração de cinco pontos (1-5), que corresponderam aos pesos numéricos associados: (1) Discordo totalmente, (2) Discordo, (3) Indiferente, (4) Concordo e (5) Concordo totalmente. Os dados obtidos foram analisados com estatística descritiva. Para cada item avaliado, foi produzido um gráfico analítico e a quantificação das medidas de variabilidade: média, amplitude e desvio padrão. Os ajustes apontados pelas avaliações realizadas pelos especialistas foram incorporados ao protótipo, para fins de geração das soluções finais. As modificações resultantes das avaliações foram:

(a) melhorar o posicionamento do banheiro, dividir em feminino e masculino, sem necessidade de área de banho (para banheiros contíguos às salas de aula), com dimensão recomendada de 1,50 m x 2,30 m — 3,45 $\mathrm{m}^{2}$ (recomenda-se áreas de banho para banheiros em áreas esportivas e vestiários);

(b) permitir acesso livre da circulação geral ao jardim, sem necessariamente passar através do ambiente de aprendizagem principal;

(c) aumentar largura das circulações fora das salas de aula, para 1,50 m (mínimo) junto às portas principais e junto aos banheiros de 1,20 m;

(d) amenizar cores muito vibrantes nas superfícies das paredes, mas manter a variedade de cores estimulantes em tons de azul, verde, amarelo e laranja;

(e) rebaixar peitoril das janelas (80 cm do piso acabado) para melhorar efeitos da ventilação na altura do corpo dos usuários e proporcionar melhores condições de acessibilidade a alavanca (altura máx. $1 \mathrm{~m}$ do piso acabado);

(f) aumentar largura das portas principais para 1,66 m em duas folhas (0,80 m cada folha), acionamento em giro completo, $180^{\circ}$ — para dentro e para fora da sala;

(g) utilizar puxadores tipo alavanca nos armários, para garantir acessibilidade das pegas, e altura de instalação não superior a $1 \mathrm{~m}$;

(h) instalar cestos (porta-trecos) no centro das mesas, quando arranjo estiver em grupo, de 5 usuários;

(i) sugerir a instalação de brise-soleils no exterior das janelas, a depender da orientação da edificação e da latitude geográfica de cada localidade; 
(j) utilizar espaço de transição (entre divisórias) para estudo individual, permitindo acesso a ambas as salas contíguas, mobiliar com pufes e almofadas para maior conforto e informalidade; e

(k) incorporar recomendações da NBR 15220 (ABNT, 2003) — zoneamento bioclimático brasileiro, para aproveitamento dos recursos climáticos das localidades.

Os resultados do desenvolvimento dos arranjos espaciais voltados a aprendizagem com blended learning apontaram para a necessidade de reconfiguração espacial e conceitual dos padrões de ambientes de aprendizagem existentes, visto a existência de padrões arquitetônicos desalinhados com as mudanças tecnológicas e paradigmáticas da aprendizagem híbrida e contemporânea. Dessa maneira, as propostas de arranjos espaciais e a conseguinte avaliação destas por usuários e especialistas definiram novos parâmetros projetuais que visam melhor qualidade do espaço de atividades de aprendizagem:

(a) quanto ao resultado formal dos leiautes e ao dimensionamento espacial (impactando no formato e na área útil ideal do espaço de aula);

(b) quanto aos conceitos espaciais associados à educação híbrida (impactando em novas ideias para ambientes de aprendizagem contemporânea), de acordo com os resultados da avaliação com usuários e especialistas; e

(c) quanto às especificações técnicas dos elementos construtivos e acabamentos internos, sistemas e aspectos de conforto ambiental, demonstradas a seguir.

\section{Resultado formal e dimensionamento espacial resultantes}

Considerando a flexibilidade espacial um princípio para atender às múltiplas atividades de aprendizagem, necessárias à aprendizagem híbrida, partiu-se de uma forma retangular (tradicional), que facilitaria tanto a execução de novas edificações quanto a de reformas de escolas existentes, mediante ajustes de instalações elétricas e hidrossanitárias, de aberturas, e de acabamentos internos.

Aspectos da configuração espacial, recomendados por Nair, Fielding e Lackney (2013) e Thornburg (1999) - CAMPFIRE (aprendizagem com um especialista); WATERING HOLE (aprendizagem com os pares); CAVE (aprendizagem por introspecção — estudo individual); LIFE (aprender fazendo), foram utilizados enquanto restrições construtivas do artefato, ao se definir que os 4 leiautes propostos deveriam oferecer:

(a) arranjo de mobiliário para aprendizagem por meio de conteúdo expositivo (plateia de frente à lousa/projetor);

(b) espaços secundários e arranjo de mobiliário para trabalho em grupo (mesas acopláveis em grupos de 5 usuários, e poltronas agrupadas aos pares em fundo do ambiente);

(c) espaço de transição com arranjo de mobiliário para aprendizagem individual por meio da leitura (compartilhado entre salas conjugadas, dotados de pufes e almofadas); e

(d) espaço da varanda e arranjo de mobiliário para trabalhos práticos e interação com o exterior (espaço para aprendizagem ao ar livre, coberto e com pia).

Internamente, a forma espacial priorizou o não paralelismo das paredes para proporcionar a conformação de um ambiente mais dinâmico e voltado a múltiplas atividades. Como demonstrado anteriormente, estudos de Nair, Fielding e Lackney (2013), Cannon Design vs Furniture e Bruce Mau Design (2010), Kowaltowski, Deliberador e Pereira (2013) e Souza (2018) demonstraram salas de aula em L, em U, em Z, como formatos mais ricos e interessantes. A forma do forro é em aclive para o fundo da sala, favorecendo o melhor desempenho acústico.

Os resultados foram ambientes com leiaute flexível, conjugados dois a dois, combinando 4 leiautes diferenciados (Figuras 4 e 5): leiaute rotação de estações (1) e leiaute atividades expositivas (2), leiaute atividades de laboratório (3) e leiaute atividades em grupo (4).

Para o dimensionamento espacial do artefato, a fim de atender a princípios de dimensionamento ergonômico e acessível adequados à realização de múltiplas atividades de aprendizagem, adotou-se uma referência de dimensionamento individual (área útil/pessoa) de $2,25 \mathrm{~m}^{2} /$ pessoa, diferentemente da relação mínima comumente aceita de $1,5 \mathrm{~m}^{2} /$ pessoa para ambientes de aprendizagem, conforme demonstrada no referencial teórico. Esta pesquisa propõe esse índice de referência (2,25 m²/pessoa) ao considerar que no espaço individual do estudante deve ser possível acomodar um usuário cadeirante e sua mesa de trabalho em qualquer posição da sala, com espaço suficiente para acomodação, circulação livre de barreiras, permitindo flexibilizar o posicionamento do mobiliário, conforme a Figura 6. Notou-se que o índice dimensional de referência de 1,5 
$\mathrm{m}^{2}$ /pessoa não é acessível, nem ergonomicamente adequado, pois não atende com conforto o módulo de referencial para pessoa com deficiência (ABNT, 2015) nem o módulo de boneco antropométrico de Panero (2016).

As soluções dos arranjos espaciais priorizaram atender as normas técnicas projetuais de referência - NBR 9050 (ABNT, 2015), NBR 90772 (ABNT, 1993), NBR ISSO CIE 8995-1 (ABNT, 2013), NBR 10152 (ABNT, 1999), NBR 15220 (ABNT, 2003) e ANSI S 12.60 (AMERICAN..., 2010), além de descrever recomendações técnicas (como demonstrado no item 4.3) para subsidiar aspectos específicos do condicionamento ambiental passivo e/ou artificial, instalações elétricas e prediais, mobiliário ergonômico, entre outros.

As áreas úteis $\left(67,50 \mathrm{~m}^{2}\right)$ são idênticas em cada leiaute, o que permite combinar essas conjugações de diversas maneiras, a depender das necessidades da escola, ou simplesmente reformular o leiaute durante a aula, obtendo uma nova organização do mobiliário, sem necessariamente mudar a turma de sala. Para dividir as salas, foram propostas divisórias acústicas removíveis. Os dados dimensionais estão descritos na Tabela 2, a seguir.

\section{Figura 4 - Leiautes de ambientes de aprendizagem relacionados com a flexibilidade necessária à} aprendizagem híbrida

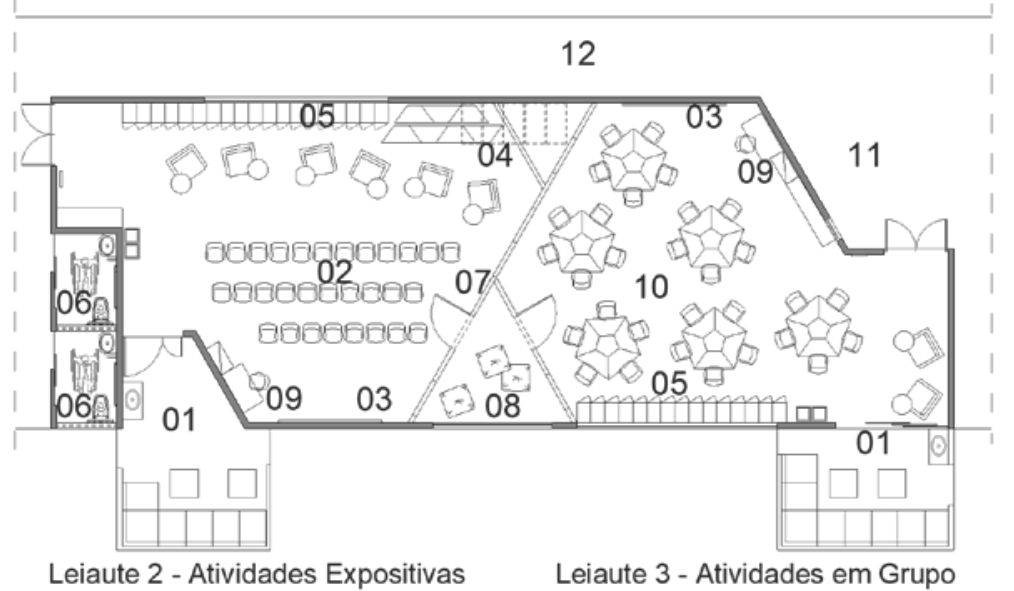

30 estudantes $=67,50 \mathrm{~m} 2-2,25 \mathrm{p} / \mathrm{m} 230$ estudantes $=67,50 \mathrm{~m} 2-2,25 \mathrm{p} / \mathrm{m} 2$

(a)

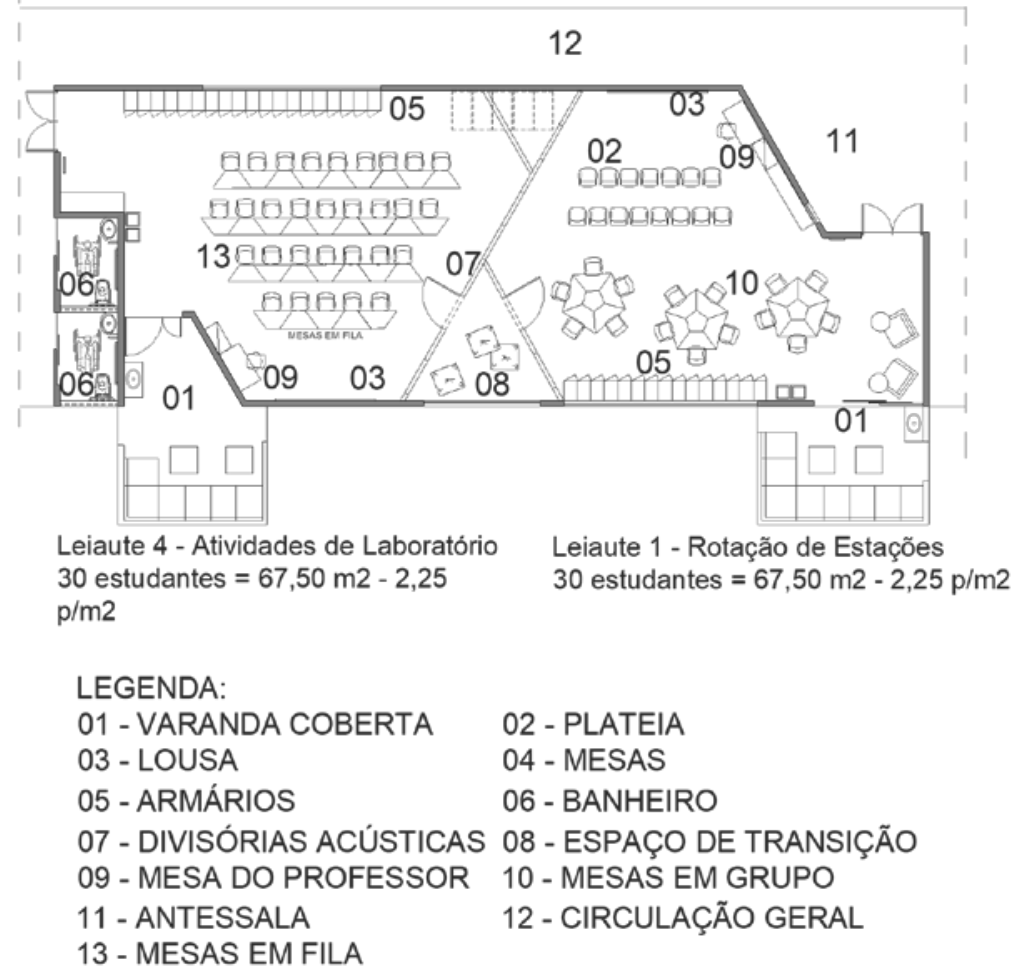


(b)

Figura 5 - Cenas do protótipo em realidade virtual

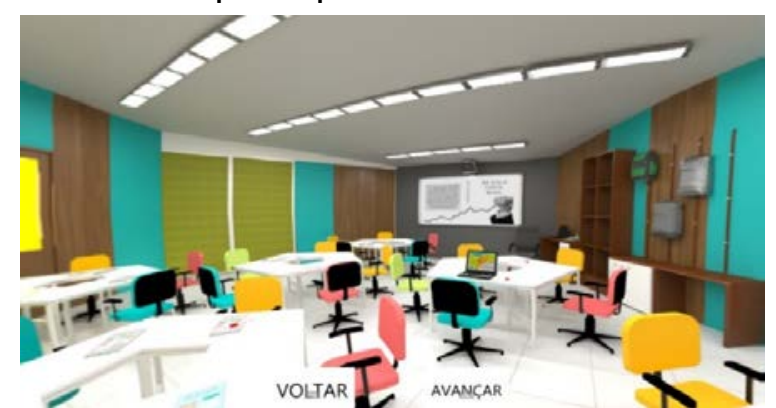

(a) Leiaute atividades em grupo

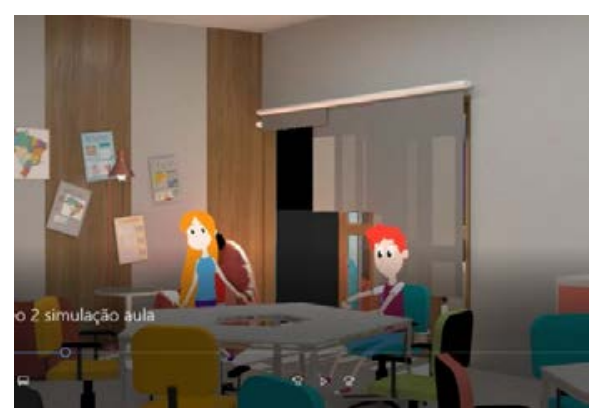

(b) Simulação de uso com personagens fictícios

Figura 6 - Índice dimensional individual proposto para ambientes de aprendizagem voltados à flexibilização espacial

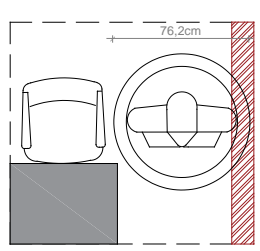

$1,5 \mathrm{~m}^{2}$ por estudante dimensionamento insuficiente e inacessível

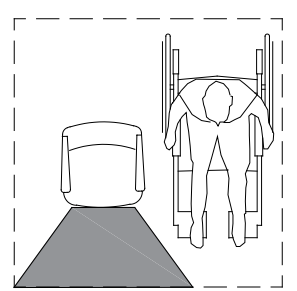

2,25 $\mathrm{m}^{2}$ por estudante dimensionamento adequado e acessível

Tabela 2 - Dados dimensionais para leiautes conjugados

\begin{tabular}{l|l|l|l}
\hline \multicolumn{4}{c}{ DADOS DIMENSIONAIS } \\
\hline Área construída $\left(\mathrm{m}^{2}\right)$ & 146,00 & Área da varanda $\left(\mathrm{m}^{2}-20 \%\right.$ A.U. $)$ & 13,50 \\
\hline Área útil interna $\left(\mathrm{m}^{2}\right)$ & 67,50 & Capacidade $\left(\mathrm{n}^{\circ}\right.$ pessoas/ambiente $)$ & 30,00 \\
\hline Altura máx. do forro $(\mathrm{m})$ & 3,00 & Densidade $\left(\mathrm{m}^{2} / \mathrm{pessoa}\right)$ & 2,25 \\
\hline Volume do recinto $\left(\mathrm{m}^{3}\right)$ & 202,50 & WCB acessível $\left(\mathrm{m}^{2}\right)$ & 7,00 \\
\hline
\end{tabular}

\section{Avaliação dos arranjos por usuários e especialistas}

Tanto para usuários quanto para especialistas, as avaliações foram majoritariamente positivas, resultando em poucos ajustes sugeridos, especialmente quanto aos aspectos de circulação interna, acionamento de esquadrias, acessibilidade e disposição de banheiros. As principais contribuições obtidas com estudantes, professores, grupos focais e especialistas, no item de contribuições individuais, foram compiladas no Quadro 4, a seguir.

Sintetizando as informações sobre as medidas de variabilidade obtidas, a Tabela 3, a seguir, mostra em ordem decrescente os índices para cada uma das questões avaliadas. Considerou-se as definições de: média = frequência $\mathrm{x}$ peso obtido/total de respondentes; amplitude = diferença entre maior e menor valor obtido; e desvio-padrão = medida média de desvio das pontuações em relação à média. Destaca-se que todos os itens avaliados obtiveram médias acima de 4 pontos (correspondente à resposta - concordo), e os três itens de melhor média obtida foram:

(a) (1) flexibilidade das soluções de leiaute e de mobiliário alinhadas às necessidades das múltiplas atividades da educação híbrida $(4,62)$;

(b) (2) espaço de trabalho do professor e o espaço junto à lousa, ambos dimensionados suficientemente, livre de barreiras visuais e físicas para melhor visualização do conteúdo em discussão $(4,60)$; e

(c) (3) escolha das cores e dos materiais associados a um ambiente acolhedor, dinâmico, iluminado e jovial $(4,56)$. 


\section{Especificações técnicas geradas para ambientes de aprendizagem adequados a blended learning}

O Quadro 5, a seguir, reúne as especificações técnicas que compõem o artefato gerado nesta pesquisa. Essas especificações são o somatório das recomendações ergonômicas obtidas com a etapa observacional em escolas que utilizam estratégias de educação híbrida, a compilação de recomendações de diferentes fontes bibliográficas e normas técnicas a respeito de aspectos construtivos, de conforto ambiental e ergonômico de edificações e de ambientes escolares.

As especificações resultantes desse artefato estão alinhadas com as propostas mais recentes de educação centrada no estudante, encontradas em espaços e ambientes escolares de países como Austrália, Estados Unidos e Inglaterra, que dispõem de pesquisas avançadas em qualidade e flexibilidade do ambiente escolar, tendo em vista as referências encontradas na revisão de literatura, que foram incorporadas aos arranjos desenvolvidos.

Quadro 4 - Síntese das principais contribuições obtidas com usuários e especialistas

\begin{tabular}{|c|c|c|c|}
\hline $\begin{array}{l}\text { CATEGORIA } \\
\text { ANALISADA }\end{array}$ & ESTUDANTES & PROFESSORES & ESPECIALISTAS \\
\hline \multirow[b]{2}{*}{$\begin{array}{l}\text { Respostas } \\
\text { iniciais sobre o } \\
\text { modelo } \\
\text { conceitual }\end{array}$} & $\begin{array}{l}\text { Respostas muito } \\
\text { positivas }\end{array}$ & Respostas positivas & $\begin{array}{l}\text { Respostas muito } \\
\text { positivas }\end{array}$ \\
\hline & $\begin{array}{l}\text { “Achei fantástico esse } \\
\text { negócio de o ambiente } \\
\text { puder mudar a todo } \\
\text { momento” Ref. } \\
\text { Estudante A. }\end{array}$ & $\begin{array}{l}\text { “As ferramentas e o dinamismo da } \\
\text { tecnologia.” Ref. Professor B }\end{array}$ & $\begin{array}{l}\text { "Realmente um } \\
\text { ambiente inovador e } \\
\text { estimulante. } \\
\text { Parabéns!" Ref. } \\
\text { Especialista E }\end{array}$ \\
\hline $\begin{array}{l}\text { Resumo das } \\
\text { observações } \\
\text { feitas com } \\
\text { relação a } \\
\text { aspectos } \\
\text { positivos } \\
\text { destacados }\end{array}$ & $\begin{array}{l}\text { Praticidade, } \\
\text { flexibilidade, espaços } \\
\text { secundários - } \\
\text { varanda e espaço de } \\
\text { transição }\end{array}$ & $\begin{array}{l}\text { Recursos tecnológicos, disposição } \\
\text { de cadeiras e mesas; possibilidade } \\
\text { de abrir as divisórias e juntar duas } \\
\text { turmas conjugadas; maior } \\
\text { produtividade e dinamismo em } \\
\text { aulas }\end{array}$ & $\begin{array}{l}\text { Espaço de trabalho } \\
\text { do professor muito } \\
\text { positivo, mas com } \\
\text { comentários em } \\
\text { relação à posição em } \\
\text { relação à turma }\end{array}$ \\
\hline $\begin{array}{l}\text { Resumo das } \\
\text { observações } \\
\text { feitas com } \\
\text { relação a } \\
\text { aspectos } \\
\text { negativos } \\
\text { destacados }\end{array}$ & $\begin{array}{l}\text { Controle dos recursos } \\
\text { ambientais somente } \\
\text { para o professor, cores } \\
\text { fortes }\end{array}$ & $\begin{array}{l}\text { Não compreensão do acesso ao } \\
\text { banheiro }\end{array}$ & $\begin{array}{l}\text { Dimensionamento } \\
\text { muito pequeno dos } \\
\text { espaços } \\
\text { complementares, } \\
\text { falta de participação } \\
\text { por gênero e } \\
\text { condições de } \\
\text { acessibilidade } \\
\text { insuficientes do } \\
\text { banheiro. }\end{array}$ \\
\hline $\begin{array}{l}\text { Comparação } \\
\text { com a } \\
\text { realidade dos } \\
\text { ambientes de } \\
\text { aprendizagem } \\
\text { atuais }\end{array}$ & $\begin{array}{l}\text { Poucos pontos em } \\
\text { comum somente para } \\
\text { alguns participantes - } \\
\text { turmas pequenas, uso } \\
\text { de lousa digital e } \\
\text { tablets. As } \\
\text { divergências são } \\
\text { maiores que as } \\
\text { similaridades } \\
\text { apontadas }\end{array}$ & $\begin{array}{l}\text { Não apontaram pontos em comum } \\
\text { entre o protótipo e a realidade dos } \\
\text { ambientes que utilizam. } \\
\text { Destacaram os problemas de } \\
\text { leiaute das salas em que lecionam, } \\
\text { e a replicação do modelo de } \\
\text { fileiras } \\
\text { Acreditam que essas mudanças } \\
\text { tecnológicas não chegarão às } \\
\text { escolas em que trabalham, por } \\
\text { questões de custo e de falta de } \\
\text { capacitação }\end{array}$ & Não mencionado \\
\hline
\end{tabular}


Tabela 3 - Medidas de variabilidade obtidas para as questões avaliadas pelos especialistas

\begin{tabular}{|c|c|c|c|}
\hline ITENS AVALIADOS & MÉDIA & AMPLITUDE & \\
\hline $\begin{array}{l}\text { As soluções de leiaute e de mobiliário estão alinhadas com } \\
\text { a flexibilidade necessária às múltiplas atividades } \\
\text { associadas à educação híbrida }\end{array}$ & 4,62 & 2,00 & 0,52 \\
\hline $\begin{array}{l}\text { Em relação ao espaço de trabalho do professor e o espaço } \\
\text { junto à lousa, ambos foram dimensionados } \\
\text { suficientemente, livre de barreiras visuais e físicas para } \\
\text { melhor visualização do conteúdo em discussão }\end{array}$ & 4,60 & 3,00 & 0,69 \\
\hline $\begin{array}{l}\text { A escolha das cores e dos materiais nas paredes, no piso e } \\
\text { no mobiliário se relacionam com um ambiente acolhedor, } \\
\text { dinâmico, iluminado e jovial }\end{array}$ & 4,56 & 3,00 & 0,64 \\
\hline $\begin{array}{l}\text { Os recursos tecnológicos adotados e as adequações } \\
\text { espaciais propostas favorecem as melhores condições de } \\
\text { infraestrutura para a aprendizagem e para a socialização } \\
\text { dos estudantes }\end{array}$ & 4,45 & 3,00 & 0,64 \\
\hline $\begin{array}{l}\text { As condições de acomodação individual e guarda de } \\
\text { pertences pessoais favorecem o conforto e a ergonomia } \\
\text { dos usuários }\end{array}$ & 4,45 & 4,00 & 0,92 \\
\hline $\begin{array}{l}\text { As estratégias e as especificações formuladas quanto ao } \\
\text { conforto acústico, térmico e lumínico contribuem para a } \\
\text { melhor adequação do ambiente às necessidades das } \\
\text { atividades educacionais }\end{array}$ & 4,41 & 3,00 & 0,69 \\
\hline $\begin{array}{l}\text { A forma do ambiente (em plateia) favorece a melhor } \\
\text { condição visual e auditiva do conteúdo em exposição, ou } \\
\text { em discussão }\end{array}$ & 4,31 & 3,00 & 0,70 \\
\hline $\begin{array}{l}\text { Os espaços secundários e de descanso estão dispostos de } \\
\text { modo acessível e confortável para o trabalho dos usuários, } \\
\text { complementando os espaços principais da aula }\end{array}$ & 4,29 & 3,00 & 0,78 \\
\hline $\begin{array}{l}\text { O posicionamento e as especificações de aberturas - } \\
\text { janelas e portas — permitem a livre circulação de ar e a } \\
\text { acessibilidade física e visual }\end{array}$ & 4,29 & 3,00 & 0,83 \\
\hline $\begin{array}{l}\text { Os conceitos subjetivos relativos à educação híbrida } \\
\text { relacionam-se, fortemente, com as soluções projetuais } \\
\text { apresentadas no protótipo }\end{array}$ & 4,23 & 3,00 & 0,83 \\
\hline
\end{tabular}

Quadro 5 - Especificações técnicas para ambientes de aprendizagem adequados ao blended learning (Continua...)

\begin{tabular}{|c|c|}
\hline ITEM & DESCRIÇÃO \\
\hline \multicolumn{2}{|r|}{$\begin{array}{l}\text { ELEMENTOS CONSTRUTIVOS } \\
\end{array}$} \\
\hline Piso & $\begin{array}{l}\text { Material e cores dos revestimentos antirreflexo, antibrilho e antiofuscamento. Superfície do piso de } \\
\text { baixa refletância - } 10 \text { a 50\%, e absorvente sonora (ILUMINATING..., 2000; ABNT, 2013). }\end{array}$ \\
\hline Paredes & $\begin{array}{l}\text { Material e cores dos revestimentos antirreflexo, antibrilho e antiofuscamento. Superfície de média } \\
\text { refletância (30\% a 80\%) nas laterais da sala, e absorvente sonora (ABNT, 2013), especialmente na } \\
\text { parede de fundo da sala para reduzir a reverberação da voz, de trás para frente (SEEP et al., 2002); } \\
\text { janelas envidraçadas localizadas na parede de fundo para boa visualização para áreas verdes no } \\
\text { exterior, e também para visualizar o corredor (NAIR; FIELDING; LACKNEY, 2013); paredes } \\
\text { laterais à lousa não paralelas, com inclinação mínima de 8\%, para evitar eco palpitante. } \\
\text { Revestimento alternado entre material absorvente sonoro - fibra de vidro com tecido e painéis } \\
\text { rebatedores sonoros (SEEP et al., 2002). }\end{array}$ \\
\hline Teto & $\begin{array}{l}\text { Forro sob o teto estrutural, ou telhado, para manter a resistência térmica interna, e retirada do ar } \\
\text { quente junto do telhado, também utilizado para refletir luz natural (KOWALTOSKI, 2011; } \\
\text { CANNON DESIGN..., 2010). Altura do forro não superior a 3,00 m, para reduzir a reverberação da } \\
\text { sala, respeitando a FDE (FUNDAÇÃO..., 2017) - pé-direito mínimo de 2,60 m, e Resolução SS- } \\
493 \text { (SECRETARIA..., 1994) - pé-direito das salas de aula médio de 3,00 m, admitindo-se o } \\
\text { mínimo em qualquer ponto de 2,50 m. }\end{array}$ \\
\hline
\end{tabular}


Quadro 5 - Especificações técnicas para ambientes de aprendizagem adequados ao blended learning (continuação)

\begin{tabular}{|c|c|}
\hline Portas & $\begin{array}{l}\text { Dimensão mínima da folha - 0,90 m × 2,10 m, para proporcionar acessibilidade. Material das } \\
\text { portas em madeira, ferro, alumínio ou PVC. Maçanetas de fácil pega, não exigindo firmeza nem } \\
\text { torção de pulso para acionamento, acabamento curvo. Altura de instalação entre } 80 \mathrm{~cm} \text { a } 110 \mathrm{~cm} \text { do } \\
\text { piso acabado. Visor translúcido, com dimensões } 20 \mathrm{~cm}(\mathrm{l}) \times 60 \mathrm{~cm} \text { (a) posicionado entre } 40 \mathrm{~cm} \text { a } 90 \\
\text { cm do piso acabado (ABNT, 2015). } \\
\text { Posicionar portas desencontradas - não frontal, e não adjacente, evitando a propagação sonora, } \\
\text { entre salas de aula (SEEP et al., 2002), com giro em } 180^{\circ} \text {, abrindo para fora do ambiente, facilitando } \\
\text { o fluxo em situações de fuga, conforme a NBR } 90772 \text { (ABNT, 1993), HEFCE (HIGHER..., 2006) e } \\
\text { Barrett et al. (2017). }\end{array}$ \\
\hline Janelas & $\begin{array}{l}\text { Folhas flexíveis e de abertura reguláveis entre dias de verão e de inverno. Material resistente nas } \\
\text { molduras, em PVC, madeira ou alumínio. Instalar barreiras luminosas, ou visuais em momentos de } \\
\text { projeção (NAIR, 2014) — blackouts de uso exclusivo para atividades com projeção. Distribuição de } \\
\text { janelas lateralmente e próximas ao fundo da sala (GUIDALLI, 2012), preferencialmente orientadas } \\
\text { em fachadas sul e norte, para evitar insolação direta nos ambientes (KOWALTOSKI, 2011). Utilizar } \\
\text { carta solar para projetar brise-soleils no exterior das janelas, mediante orientação da edificação } \\
\text { (variável para cada implantação). Altura dos peitoris de até } 1 \text { m, do piso acabado, permitindo } \\
\text { ventilação na altura do corpo dos usuários. Junto à lousa não terá janelas, para evitar problema de } \\
\text { reflexo de luz no quadro negro/lousa (NAIR, 2014; KOWALTOSKI, 2011). }\end{array}$ \\
\hline $\begin{array}{l}\text { Leiaute e área } \\
\text { útil }\end{array}$ & $\begin{array}{l}\text { Espaço livre entre as mesas e cadeiras de } 1,00 \text { m. Deve ter espaço para armazenar objetos de } \\
\text { trabalho e dos estudantes. Junto à lousa, deve haver uma área livre de } 3 \mathrm{~m}^{2} \text { para circulação do orador } \\
\text { (LITTLEFIELD, 2011). Leiaute flexível, que possibilite diferentes organizações - lineares } \\
\text { (favorecem a concentração e o trabalho individual (FERNANDES; HUANG; RINALDO, 2011); em } \\
\text { semicírculos, ou em U (favorecem a interação e comunicação em atividades colaborativas } \\
\text { (ATTAIANESE, 2017). }\end{array}$ \\
\hline Uso da cor & $\begin{array}{l}\text { Cor para organizar, personalizar ou tornar o espaço mais acessível. Priorizar o conforto visual dos } \\
\text { estudantes, evitar a fadiga visual e a monotonia (GUIDALLI; BINS ELY, 2013). Cor mais escura ou } \\
\text { complementar aplicada na parede da lousa, reduzindo a fadiga ocular (CANNON DESIGN..., 2010); }\end{array}$ \\
\hline Varanda & $\begin{array}{l}\text { Espaço de aprendizagem informal, para convivência, relaxamento e contemplação da natureza, } \\
\text { sombreado e dotado de mobiliário confortável e variado. Uso para lanches, leitura individual e } \\
\text { atividades em grupo. Deve haver boa visualização, por janelas envidraçadas, entre a sala de aula e a } \\
\text { varanda (NAIR, 2014). Deve haver pia para possibilitar realizar trabalhos práticos, com uso de } \\
\text { materiais de modelagem - gesso, argila, tintas, etc. }\end{array}$ \\
\hline Banheiro & $\begin{array}{l}\text { Banheiro próximo da sala de aula, de fácil supervisionamento (LITTLEFIELD, 2011), configuração } \\
\text { doméstica (pia, vaso e chuveiro no mesmo ambiente) garantindo maior privacidade (NAIR; } \\
\text { FIELDING; LACKNEY, 2013). Acessórios como: porta-sabonete, pendurador de bolsa/casacos, } \\
\text { espelho sobre a pia, e ducha higiênica, são indispensáveis. Se houver cabines internas, as portas e as } \\
\text { divisões devem ser inteiras (do piso ao teto). } \\
\text { Partição entre banheiro feminino e masculino, e o dimensionamento mínimo de } 1 \text { vaso sanitário e } 1 \\
\text { lavatório para cada } 20 \text { estudantes. Deve haver tranca com chave nas portas, janelas com aberturas } \\
\text { para ventilação ao exterior da edificação, boa iluminação e manutenção periódica. }\end{array}$ \\
\hline \multicolumn{2}{|r|}{ SISTEMAS } \\
\hline $\begin{array}{l}\text { Energia - } \\
\text { tomadas }\end{array}$ & $\begin{array}{l}\text { Disposição de tomadas, inclusive no piso, permitindo ligar carregadores de celulares e de laptops } \\
\text { sobre as mesas dos estudantes (LITTLEFIELD, 2011; NAIR, 2014); Instalação de rodapé técnico, } \\
\text { permite passar fiação elétrica e abrir novos pontos de energia em todo o perímetro do ambiente. }\end{array}$ \\
\hline $\begin{array}{l}\text { Energia - } \\
\text { Iluminação }\end{array}$ & $\begin{array}{l}\text { Iluminação geral dinâmica que alterne luz do dia, relacionada à temperatura da cor, variando por } \\
\text { atividade, sem ofuscamento para uso confortável de computadores e tablets (CORREA; LOPES, } \\
\text { 2006); iluminação específica para lousa, cuidando que não haja vazamento de luz para a tela de } \\
\text { projeção nem para a plateia, com índice de } 500 \text { lux (ABNT, 2013), (SLEEGERS et al., 2013); na } \\
\text { área de mesas de trabalho, usar luz direta, com lâmpadas suave (luz do dia), com boa reprodução de } \\
\text { cores, com fluxo médio entre } 300 \text { e } 500 \text { lux (SLEEGERS et al., 2013), e lâmpadas com IRC no } \\
\text { mínimo de } 80 . \\
\text { Proporcionar luminárias nas mesas de trabalho para tarefas de maior precisão; Sistema de controle } \\
\text { de iluminação sem fio, facilitam o controle dos cenários - com detectores de luz do dia e ajuste } \\
\text { automático dos níveis de iluminação das luminárias. Acionamento automático de luminárias por filas } \\
\text { (paralelas às janelas) a serem acionadas, na medida em que a luz natural diminui sua intensidade. Os } \\
\text { controles manuais de iluminação devem ser subdivididos por áreas, e precisam ser identificados } \\
\text { nominalmente. Os interruptores devem estar localizados perto das estações de trabalho, além de } \\
\text { próximos às portas. Deve haver uma chave geral que comande a iluminação total da sala, localizada } \\
\text { próxima a cada porta. }\end{array}$ \\
\hline
\end{tabular}


Quadro 5 - Especificações técnicas para ambientes de aprendizagem adequados ao blended learning (continuação)

\begin{tabular}{|c|c|}
\hline Internet & $\begin{array}{l}\text { Dispor de uma sala de controle de recursos tecnológicos, para suporte técnico aos equipamentos } \\
\text { digitais e a gestão do conteúdo; rede Wi-Fi de alta capacidade que suporte acesso do grande número } \\
\text { de estudantes (NAIR, 2014; NAIR; FIELDING; LACKNEY, 2013); uso de internet Wi-Fi para } \\
\text { divulgação e pesquisa de conteúdo educacional, entre turmas da escola, e também junto à } \\
\text { comunidade; progressão do controle de acesso à internet, do totalmente controlado para o totalmente } \\
\text { livre, de acordo com os horários de estudo, idade e maturidade dos estudantes. }\end{array}$ \\
\hline $\begin{array}{l}\text { Gestão e } \\
\text { compartilha- } \\
\text { mento da } \\
\text { aprendizagem }\end{array}$ & $\begin{array}{l}\text { Conexão Wi-Fi entre ambiente físico e ambiente on-line de aula, para compartilhamento de conteúdo } \\
\text { educacional, comunicação entre professores, pais e estudantes, acesso a atividades educativas à } \\
\text { distância e ao rendimento escolar do estudante; compartilhamento da produção dos estudantes } \\
\text { através da internet com a comunidade local, e com outros estudantes. }\end{array}$ \\
\hline \multicolumn{2}{|r|}{ CONFORTO AMBIENTAL } \\
\hline $\begin{array}{l}\text { Condiciona- } \\
\text { mento } \\
\text { acústico geral }\end{array}$ & $\begin{array}{l}\text { As condições acústicas entre (35 - } 40 \mathrm{~dB} \text { de ruído de fundo) com o orador falando com sua voz } \\
\text { normal (65 dB), mantendo a relação fala/ruído acima de } 10 \mathrm{~dB} \text {, para evitar interferências na } \\
\text { inteligibilidade da fala (SEEP et al., 2002; AMERICAN..., 2010); a sala deve ser livre de ecos e de } \\
\text { outros fenômenos acústicos que possam confundir ou distorcer o som a ser ouvido (KOWALTOSKI } \\
\text { et al., 2001; DUDEK, 2007); tempo de reverberação (ideal) entre 0,4 a 0,6 s, alta capacidade de } \\
\text { absorção das superfícies de paredes e teto; a geometria da sala projetada para permitir a melhor } \\
\text { difusão do som, paredes laterais não paralelas, evitando ecos; revestimentos internos e de mobiliário } \\
\text { macios, com uso de tecidos e fibras (SEEP et al., 2002). }\end{array}$ \\
\hline $\begin{array}{l}\text { Forro } \\
\text { Acústico }\end{array}$ & $\begin{array}{l}\text { Altura do forro não superior a } 3 \text { m, evitando a reverberação sonora; superfície do forro de alta } \\
\text { refletância - 60\% a 90\% (AMERICAN..., 2010), principalmente junto à lousa, e ao centro da sala. } \\
\text { Forro acústico com NRC de 0,75 ao redor do perímetro das paredes. Forro do centro da sala em } \\
\text { material refletor (gesso), responsável por espalhar a voz do orador (SEEP et al., 2002). }\end{array}$ \\
\hline $\begin{array}{l}\text { Divisórias (se } \\
\text { necessárias) }\end{array}$ & $\begin{array}{l}\text { Divisórias acústicas revestidas em lã de vidro ou fibra mineral, dispostas em painéis verticais. Evitar } \\
\text { propagação de ruído sobre o forro acústico (SEEP et al., 2002); as divisórias móveis podem ser úteis } \\
\text { para possibilitar a junção de duas salas de aula, em atividades colaborativas entre turmas ou mudar o } \\
\text { uso da sala. }\end{array}$ \\
\hline $\begin{array}{l}\text { Controle } \\
\text { ambiental - } \\
\text { iluminação, } \\
\text { condiciona- } \\
\text { mento de ar }\end{array}$ & $\begin{array}{l}\text { Priorização da luz natural indireta, e possibilidade de controle, para obscurecimento. Proteção contra } \\
\text { a insolação direta, pela instalação de brise-soleils (leves e de fácil manuseio) ou beirais, e de } \\
\text { prateleiras de luz que conduzem a luz mais profundamente no ambiente (GUIDALLI; BINS ELY, } \\
\text { 2013), utilizar carta solar para projetar brise-soleils no exterior das janelas, mediante orientação da } \\
\text { edificação; aplicar a NBR } 15220 \text { (ABNT, 2003) para aproveitamento das estratégias e } \\
\text { condicionamento ambiental passivo; manutenção da temperatura interna do ar em } 23^{\circ} \text { C, e janelas } \\
\text { instaladas na altura das pessoas sentadas (KOWALTOWSKI, 2011; BERTOLOTTI, 2007; } \\
\text { HESCHONG..., 2003); se necessário usar sistema de condicionamento de ar com regulagem } \\
\text { automática de temperatura e umidade. } \\
\text { Evitar equipamentos de condicionamento de ar com alto nível sonoro, e instalar suas fontes } \\
\text { geradoras fora da sala de aula. Ao usar dutos de ventilação, favorecer aqueles de dimensões que } \\
\text { proporcionem baixa velocidade do ar, e NC - critério de ruído, abaixo de } 20 \text { a } 25 \text { (SEEP et al., } \\
\text { 2002). Usar controle de iluminação artificial sem fio, para facilitar o controle dos cenários - com } \\
\text { detectores de luz do dia e ajuste automático dos níveis de iluminação das luminárias. Acionamento } \\
\text { automático de liga/desliga, por sensores de presença. }\end{array}$ \\
\hline \multicolumn{2}{|r|}{ MOBILIÁRIO E EQUIPAMENTOS } \\
\hline Geral & $\begin{array}{l}\text { Mobiliário variado (hard and soft — rígidos e macios) (NAIR; FIELDING; LACKNEY, 2013), com } \\
\text { flexibilidade de uso, permitindo variação de arranjos; mesas individuais acessíveis à pessoa com } \\
\text { cadeira de rodas (rodas e travas para mesas, cadeiras e prateleiras). Tampos e quinas arrematadas } \\
\text { (NAIR, 2014; EUROPEAN..., 2015). }\end{array}$ \\
\hline Cadeiras & $\begin{array}{l}\text { Elementos ajustáveis para o sistema de assento — cadeira - mesa — apoio para os pés, em relação } \\
\text { ao tamanho, durante o uso do mobiliário, e de ajuste do conjunto mesa - cadeira para o tamanho (a } \\
\text { idade), garantindo o princípio de sentar-dinâmico (NOWAKOWSKI, 2010; CARNIDE, 2006); o } \\
\text { encosto deve inclinar para trás e para a frente com descanso ajustável para as costas, formando } \\
\text { ângulo obtuso }\left(95-110^{\circ} \text { ) entre o assento e o encosto; deve apoiar a lombar da coluna, tanto na }\right. \\
\text { posição reta e quando inclinado para a frente ou para trás (EUROPEAN..., 2015). Os assentos } \\
\text { devem ser macios para absorver ruídos, o perfil da parte da frente do assento não deve pressionar as } \\
\text { coxas na curvatura do joelho. }\end{array}$ \\
\hline
\end{tabular}


Quadro 5 - Especificações técnicas para ambientes de aprendizagem adequados ao blended learning (continuação)

\begin{tabular}{|c|c|}
\hline Mesas & $\begin{array}{l}\text { Tampos - permitindo inclinação, com revestimentos antiderrapantes; e em tamanho que permita o } \\
\text { apoio de ambos os antebraços e cotovelos (MANDAL, 1976; FREUDENTHAL et al., 1991). As } \\
\text { mesas, quando agrupadas em conjuntos, devem ter cestos no centro, para acomodar papéis, canetas, } \\
\text { lápis. O espaço de trabalho individual deve permitir que computadores, tablets e smartphones sejam } \\
\text { acomodados (NOWAKOWSKI, 2010; POLLOCK; STRAKER, 2008); Estruturas leves em } \\
\text { alumínio e tampo em BP formato trapezoidal. Dimensionamento médio: } 55 \mathrm{~cm}(\mathrm{p}) \times 100 \mathrm{~cm} \text { (l), } \\
\text { revestimento melamínico cor clara, e bordas arrematadas. Os pés com rodízios que facilitem o } \\
\text { deslocamento, o empilhamento e o agrupamento das mesas para atividades em grupo. }\end{array}$ \\
\hline Poltronas & $\begin{array}{l}\text { Assentos macios em espaços menores da sala, ideais para momento de concentração e estudo } \\
\text { individual. Dimensionamento médio: } 70 \mathrm{~cm}(\mathrm{l}) \times 70 \mathrm{~cm}(\mathrm{p}) \times 45 \mathrm{~cm} \text { (alt. assento). Associar a } \\
\text { grandes almofadas individuais, ou em grupo no chão. }\end{array}$ \\
\hline Armários & $\begin{array}{l}\text { Armários individuais próximos às mesas de trabalho, com portas e chaves, para guarda de pertences } \\
\text { pessoais; materiais confortáveis, duráveis e coloridos, passíveis de personalização — com desenhos, } \\
\text { etiquetas, cores e fotografias; dimensionamento médio: } 35 \mathrm{~cm}(\mathrm{l}) \times 40 \mathrm{~cm}(\mathrm{p}) \times 75 \mathrm{~cm}(\mathrm{a}) \text {, maior } \\
\text { que os armários convencionais, a fim de armazenar laptops, com puxadores tipo alavanca, bordas } \\
\text { arredondadas e espaço suficiente para pega e manuseio acessível, a altura da instalação dos } \\
\text { puxadores deve permitir manuseio em cadeira de rodas. O armário do professor deve acomodar } \\
\text { livros, papéis e pastas, com espaços abertos e também fechados com chaves. Os nichos para abrigar } \\
\text { caixas e grandes volumes devem estar posicionados próximos ao piso, com largura que permita } \\
\text { abrigar grandes volumes. Os penduradores de mochilas devem suportar peso suficiente para } \\
\text { acomodar volumes dos livros e laptops, suas instalações devem permitir o acesso de pessoas de } \\
\text { diferentes estaturas, desde } 1,00 \mathrm{~m} \text { a 1,50 m. }\end{array}$ \\
\hline $\begin{array}{l}\text { Estação de } \\
\text { trabalho do } \\
\text { professor }\end{array}$ & $\begin{array}{l}\text { Mesa de trabalho leve, sob rodas, que permita: mudar de posição (de frente ou não para a turma); } \\
\text { além de acomodar computador e impressora, com iluminação de tarefa, ponto de energia e de } \\
\text { internet, permitindo realizar a gestão dos recursos digitais - uso de internet Wi-Fi e cabeada, } \\
\text { acesso aos comandos de condicionamento ambiental - iluminação artificial, condicionamento de } \\
\text { ar, controle de blackout, equipamentos de áudio, vídeo e projeção. Dimensionamento médio: } 100 \mathrm{~cm} \\
(\mathrm{l}) \times 60 \mathrm{~cm}(\mathrm{p}) \times 72 \mathrm{~cm}(\text { alt. tampo). Cadeira confortável, com rodízio, apoio de braços, com } \\
\text { regulagem de assento e encosto. Dimensionamento médio: } 70 \mathrm{~cm}(\mathrm{l}) \times 70 \mathrm{~cm}(\mathrm{p}) \times 45 \mathrm{~cm}(\text { alt. } \\
\text { assento). Armário, ou estante acoplada a mesa, com rodízio e travas, para abrigar trabalhos dos } \\
\text { estudantes e material didático, com portas e prateleiras, de acordo com a descrição do item acima } \\
\text { (armários). }\end{array}$ \\
\hline $\begin{array}{l}\text { Móveis para } \\
\text { varanda }\end{array}$ & $\begin{array}{l}\text { Mesas e cadeiras leves e coloridas para acomodar muitas pessoas. Dispor de almofadas, bancos e } \\
\text { desníveis promovendo oportunidades de relaxamento e de convivência. Dispor de instalação de } \\
\text { ponto de água e esgoto, em caso de uso de pia para trabalhos práticos com materiais de modelagem } \\
\text { — barro, tinta, gesso, etc. }\end{array}$ \\
\hline Cortinas & Cortina de acionamento por controle remoto, em fibra de poliéster, tipo blackout, na cor branca. \\
\hline \multirow{4}{*}{ Equipamentos } & $\begin{array}{l}\text { Lousas acessíveis e instaladas a uma altura inferior máxima de } 90 \mathrm{~cm} \text { do piso. Combinação de lousa } \\
\text { digital e tradicional acopladas no mesmo equipamento a fim de facilitar a demonstração dos } \\
\text { conteúdos em atividade expositiva. Dimensões totais da lousa de } 260 \mathrm{~cm}(\mathrm{l}) \times 120 \mathrm{~cm}(\mathrm{a}) \text {. }\end{array}$ \\
\hline & $\begin{array}{l}\text { Projetores - instalação acoplada à lousa (lousa digital) e ao computador de trabalho expositivo da } \\
\text { sala. O computador deve estar posicionado sobre uma mesa, localizada nas proximidades da lousa, } \\
\text { sem obstruir (nem visualmente, nem com instalações e fios) o espaço de circulação frontal na sala. } \\
\text { Dimensão da projeção em tela interativa } 160 \mathrm{~cm}(\mathrm{l}) \times 120 \mathrm{~cm} \text { (a). }\end{array}$ \\
\hline & $\begin{array}{l}\text { Equipamentos de uso educacional - como impressoras e computadores devem estar conectados } \\
\text { em rede, e disponíveis para utilização, sempre em bom estado de conservação e de manutenção. Fios } \\
\text { e cabos instalados em rodapé técnico, não obstruir a circulação, e suas tomadas devem estar } \\
\text { posicionadas nas paredes mais próximas dos respectivos equipamentos, se necessário reposicionar } \\
\text { tomadas ao longo de rodapés técnicos, e não utilizar extensores. Altura acessível das tomadas de } 65 \\
\text { cm a } 75 \text { cm do piso acabado. }\end{array}$ \\
\hline & $\begin{array}{l}\text { Equipamentos de uso pessoal — como laptops, tablets e celulares devem ser usados livremente } \\
\text { pelos estudantes, proporcionando compartilhamento de informações e socialização, através da uma } \\
\text { rede WI-FI estável e aberta. Deve haver facilidade de recarga de energia para esses equipamentos, } \\
\text { com pontos de energia distribuídos em toda a sala, no piso ou sobre as mesas. }\end{array}$ \\
\hline
\end{tabular}

As inovações propostas para padrões de ambientes de aprendizagem em escolas públicas brasileiras foram baseadas nesses estudos, entretanto com foco em uma fase de adequação aos formatos tradicionais de ensino e de ambientes de aprendizagem, que estão se modificando no país, como observa Moran (2015) e Gomes e Silva (2016), diante da implantação das TICs nas escolas brasileiras. Soma-se a isso a análise da precariedade de infraestrutura básica nas escolas brasileiras (relatada no Censo Escolar 2017 (INSTUTUTI..., 2018)), a 
diferença de padrões construtivos escolares encontrados nas regiões mais desenvolvidas (sul e sudeste) e menos desenvolvidas (norte e nordeste) do Brasil. Dessa maneira, não seria social ou culturalmente viável propor alterações tão significativas quanto às encontradas em países mais avançados, já que a arquitetura, como assinatura local, deve se relacionar com os aspectos sociais e temporais da sua comunidade.

\section{Considerações finais}

Esta pesquisa contribui para a área de estudos sobre ambientes escolares, demonstrando inconsistências entre os tradicionais padrões dimensionais de referência para ambientes de aprendizagem de escolas públicas no Brasil, frente aos desafios para implantação de uma educação enriquecida com novas tecnologias.

É importante destacar o desafio de utilizar o método DSR como forma de demonstrar evidências robustas para o desenvolvimento de modelo e protótipos de ambientes construídos. O artefato desenvolvido apresentou, inicialmente, alguns equívocos projetuais, que foram detectados, principalmente, por profissionais especialistas, contribuindo para sua evolução posterior. Foi positivo usar um artefato virtual para essa avaliação durante o processo de projeto. O artefato foi composto por representações em 2-D e em 3-D, e audiodescrição dos elementos do projeto, que possibilitaram a simulação de diferentes modalidades de aprendizagem, ocorrendo em um mesmo espaço físico. Isto possibilitou aos avaliadores emitir críticas e sugestões, em um processo participativo, tanto em grupos focais (com usuários finais), como em avaliações individuais (com especialistas). Essas avaliações seriam difíceis de serem obtidas somente com discussões ou debates sobre temas conceituais. Portanto, o DSR associado às ferramentas de design participativo, ideação, prototipação e avaliação (com usuários e especialistas) é um método de pesquisa eficiente para pesquisas na área de projeto de arquitetura, de urbanismo e de design de interiores.

Longe de pretender encerrar a pesquisa sobre o tema abordado, as especificações técnicas, enquanto produtos da pesquisa, visam reunir informações precisas (que por vezes encontram-se dispersas em fontes bibliográficas diferentes) voltadas à aplicação em projetos arquitetônicos e de interiores escolares, com relação ao dimensionamento, ao conforto ambiental e ergonômico, à seleção de elementos construtivos, de mobiliário e de equipamentos para leiautes de ambientes escolares voltados a práticas educacionais adequadas ao blended learning. $\mathrm{O}$ uso de ferramentas de realidade virtual para avaliar o artefato desenvolvido foi uma experiência enriquecedora, possibilitando obter a percepção de usuários e de especialistas sobre diferentes aspectos do ambiente projetado antes mesmo de sua construção, antecipando assim inadequações futuras não observadas na fase projetual. Recomenda-se que em futuras pesquisas os estudos avancem para a prototipação em tamanho real de novos leiautes de ambientes de aprendizagem, permitindo aos usuários experimentar situações reais de uso, e assim efetuar avaliações quantitativas com melhor precisão.

\section{Referências}

ALCANTARA, P. G. de F. Análise de parâmetros de condições acústicas nas escolas municipais da cidade de João Pessoa. In: ENCONTRO NACIONAL DE ERGONOMIA DO AMBIENTE CONSTRUÍDO, 3., João Pessoa,2011. Anais [...] João Pessoa: UFPB, 2011.

AMERICAN NATIONAL STANDARD INSTITUTE. S 12.60: acoustical performance criteria, design requirements, and guidelines for schools. Lancaster, 2010.

ARCHDAILY.COM. Vittra Telefonplan/ Rosan Bosch. Archidaily, 2012. Disponível em: <http://www.archdaily.com/202358/vittra-telefonplan-rosan-bosch>. Acesso em: 12 mar. 2016.

ARIZONA STATE UNIVERSITY. Classroom design guide. University Classrooms - Space Management. Arizona, 2013. Disponível em: <http://cfo.asu.edu/fdm-ucl-space-mgmt>. Acesso em: 25 ago. 2018.

ASSOCIAÇÃO BRASILEIRA DE NORMAS TÉCNICAS. NBR 10152: acústica: avaliação do ruído ambiente em recintos de edificações visando o conforto dos usuários: procedimento. Rio de janeiro, 1999.

ASSOCIAÇÃO BRASILEIRA DE NORMAS TÉCNICAS. NBR 15220: desempenho térmico de edificações Parte 3: zoneamento bioclimático brasileiro e diretrizes construtivas para habitações unifamiliares de interesse social. Rio de Janeiro, 2003.

ASSOCIAÇÃO BRASILEIRA DE NORMAS TÉCNICAS. NBR 9050: acessibilidade a edificações, mobiliário e equipamentos urbanos. Rio de Janeiro, 2015.

ASSOCIAÇÃO BRASILEIRA DE NORMAS TÉCNICAS. NBR 90772: saída de emergência em edifícios. Rio de janeiro, 1993. 
ASSOCIAÇÃO BRASILEIRA DE NORMAS TÉCNICAS. NBR ISO/CIE 8995-1: iluminação de ambientes de trabalho: parte 1: interior. Rio de Janeiro, 2013.

ATTAIANESE, E.; DUCA, G. Human factors and ergonomic principles in building design for life and work activities: an applied methodology. Theoretical Issues in Ergonomics Science, London, v. 13, n. 2, p. 187202, 2012.

ATTAIANESE, E. Ergonomia e Comfort a scuola. In: SEMINARIO FOCUS SULLA SALUTE E SICUREZZA NELLE SCUOLE: FORMAZIONE, ERGONOMI, ANTINCENDIO E RISCHI PSICOSOCIALI, 2., Petriccione, 2017. Presentazione [...]. Napoli: UNINA, 2017.

BACICH, L.; TANZI NETO, A.; TREVISANI, F. M. (orgs.) Ensino Híbrido: personalização e tecnologia na educação. Porto Alegre: Penso, 2015.

BARRETT, P. et al. the impact of classroom design on pupils' learning: final results of a holistic, multilevel analysis. Building and Environment, v. 89, p. 118-133, 2015.

BARRETT, P. et al. the holistic impact of classroom spaces on learning in specific subjects. Environment and Behavior, v. 49, n. 4, p.425-451, 2017.

BERTOLOTTI, D. Iluminação natural em projetos de escolas: uma proposta de metodologia para melhorar a qualidade da iluminação e conservar a energia. São Paulo, 2007. Dissertação (Mestrado em Arquitetura e Urbanismo) - Faculdade de Arquitetura e Urbanismo, Universidade de São Paulo, São Paulo, 2007.

BLUYSSEN, P. M. Health, comfort and performance of children in classrooms: new directions for research. Indoor and Built Environment, v. 26, n. 8, p. 1040-1050, 2017.

BOWERS, B. Disrupting determinism: classroom design as a technology. CEA Forum, v. 39, n.1, p.108117, 2010.

CANNON DESIGN VS FURNITURE; BRUCE MAU DESIGN. The third teacher: a collaborative project. New York: Abrams, 2010.

CARLE, A. C.; JAFFEE, D.; MILLER, D. Engaging college science students and changing academic achievement with technology: a quasi-experimental preliminary investigation. Computer \& Education, v. 52, p. 376-380, 2009.

CARNIDE, M. F. Ergonomia escolar, recomendações. Direção Geral da Saúde - Programa Nacional de Saúde Escolar e Programa Nacional contra as Doenças Reumáticas. Faculdade de Motricidade Humana. Lisboa, 2006. Disponível em: http://www.dgs.pt/ficheiros-de-upload-3/pncdr-recom-ergonomiaescolar_final-out06-pdf.aspx. Acesso em: 10 ago. 2015.

CHAN, T. C.; RICHARDSON, M. D. Ins and outs of school facility management: more than bricks and mortar. Lanham, MD: Scarecrow Education, 2005.

CORNELL, P. The impact of changes in teaching and learning on furniture and the learning environment. New Directions for Teaching and Learning, v. 2002, n. 92, p. 33-42, 2002.

CORNELIUS-WHITE, J. Learner-centered teacher-student relationships are effective: A meta-analysis.

Review of Educational Research, v. 77, n. 1, p. 113-143, 2007.

CORRÊA, S. R. M.; LOPES, A. C. D. S. Estudo de caso: proposta de adequação do sistema de iluminação suplementar em sala de aula padrão da rede municipal de Florianópolis. In: ENCONTRO NACIONAL DE TECNOLOGIA NO AMBIENTE CONSTRUÍDO, 11., Florianópolis, 2006. Anais [...] Florianópolis: UFSC, ANTAC, 2006.

DRESCH, A.; LACERDA, D. P.; ANTUNES JUNIOR, J. A. V. Design science research: método de pesquisa para avanço da ciência e tecnologia. Porto Alegre: Bookman, 2015.

DUDEK, M. Schools and kindgartens: a design manual. Basel Boston: Birkhäuser, 2007.

EUROPEAN COMMITTEE FOR STANDARDIZATION. EN 1729-1: furniture: chairs and tables for educational institutes: part 1: functional dimensions. 2015.

FERNANDES, A. C.; HUANG, J.; RINALDO, V. Does where a student sits really matter? The impact of seating locations on student classroom learning. International Journal of Applied Educational Studies, v. 10, n. 1, p. 66-77, 2011. 
FRASER, B. J. Classroom climate. International Encyclopedia of the Social \& Behavioral Sciences, v. 3, p. 825-832, 2015.

FREIBERG, J. H.; LAMB, S. M. Dimensions of person-centered classroom management. Theory into Practice, v. 48, n. 2, p. 99-105, 2009.

FREUDENTHAL, A. et al. The effect on sitting posture of a desk with a ten-degree inclination using an adjustable chair and table. Applied Ergonomics, v. 22, n. 5, p. 329-36, 1991.

FUNDAÇÃO PARA O DESENVOLVIMENTO DA EDUCAÇÃO. Catálogos de ambiente: especificações da edificação escolar. São Paulo: Governo do Estado de São Paulo/FDE, 2017. Disponível em:

$<$ https://produtostecnicos.fde.sp.gov.br/Pages/CatalogosTecnicos>. Acesso em: 20 ago. 2017.

FUNDESCOLA; MINISTÉRIO DA EDUCAÇÃO. Ensino fundamental: mobiliário escolar. Série Cadernos Técnicos 1, n. 3. Brasília: MEC, 1999.

FUNDESCOLA; MINISTÉRIO DA EDUCAÇÃO. Espaços educativos. In: SOUZA, J. M. A. (coord.). Ensino fundamental, subsídios para elaboração de projetos escolares e adequação de edificações escolares. Brasília: FUNDESCOLA/ MEC, 2002.

GOMES, A. S. et al. Cultura digital na escola: habilidades, experiências e novas práticas. Recife: Pipa Comunicação, 2015. (Série professor criativo, I). Série Professor Criativo.

GOMES, A. S.; SILVA, P. A. Design de Experiências de Aprendizagem: criatividade e inovação para o planejamento de aulas. Recife: Pipa Comunicação, 2016. (Série professor criativo, III).

GUIDALLI, C. R. R. Diretrizes para o projeto de salas de aula em universidades visando o bem-estar do usuário. Florianópolis, 2012. Dissertação (Mestrado em Arquitetura e Urbanismo) - Faculdade de Arquitetura e Urbanismo, Universidade Federal de Santa Catarina, Florianópolis, 2012.

GUIDALLI, C. R. R.; BINS ELY, V. H. M. Conforto visual nas salas de aula de universidades. In: ENCONTRO NACIONAL DE ERGONOMIA DO AMBIENTE CONSTRUÍDO, 6., Florianópolis, 2013. Anais [...] Florianópolis: UFSC, 2013.

GURGEL, M. Design Passivo, baixo consumo energético: guia para conhecer, entender e aplicar os princípios do Design Passivo em residências. São Paulo: Ed. Senac São Paulo, 2012.

HIGHER EDUCATION FUNDING COUNCIL FOR ENGLAND. Designing spaces for effective learning: a guide to $21^{\text {st }}$ century learning space design. JISC e-Learning Programme, Bristol, 2006. Disponível em: <https://www.webarchive.org.uk/wayback/archive/20140614213943/http://www.jisc.ac.uk/publications/pro grammerelated/2006/pub_spaces.aspx>. Acesso em: 10 fev. 2017.

HERMANS, R. et al. The impact of primary school teachers' educational beliefs on the classroom use of computers, Computers \& Education, v. 51, p. 1499-1509, 2008.

HESCHONG MAHONE GROUP. Windows and classrooms: a study of student performance and the indoor environment. Sacramento, 2003.

HESCHONG, L.; MAHONE, D. Daylighting in school: an investigation into the relationship between daylighting and human performance. Fair Oaks: Pacific Gas and Eletric Company, 1999.

HORN, M.; STAKER, H. Blended: usando a inovação disruptiva para aprimorar a educação. Porto Alegre: Penso, 2015.

HUANG, R. et al. The Functions of smart classroom in smart learning age. Open Education Research, v. 2012, p. 22-27, 2012.

ILUMINATING ENGINEERING SOCIETY OF NORTH AMERICA. Lighting handbook, reference and application. 9. ed. New York: IESNA, 2000.

INSTITUTO NACIONAL DE ESTUDOS E PESQUISAS EDUCACIONAIS ANÍSIO TEIXEIRA. Censo Escolar 2017: notas estatísticas. Brasília: INEP/MEC, 2018. Disponível em:

<http://download.inep.gov.br/educacao_basica/censo_escolar/notas_estatisticas/2018/notas_estatisticas_Cen so_Escolar_2017.pdf $>$. Acesso em: 20 out. 2018.

KAUP, M. L.; KIM, H.; DUDEK, M. Planning to learn: the role of interior design in educational settings. International Journal of Design for Learning, v. 4, n. 2, p. 41-55, 2013. 
KIM, M. C.; HANNAFIN, M. J. Scaffold in problem solving in technology-enhanced learning environments (TELEs): bridging research and theory with practice. Computers \& Education, v. 56, p. 403-417, 2011.

KOWALTOSKI, D. C. C. K.; DELIBERADOR, M. S.; PEREIRA, P. R. P. Designing the positive publicschool environment: a Brazilian perspective. In: ZANNIN, P. H. T. (org.). Noise and ergonomics in the workplace. New York: Nova Science Publishers, 2013.

KOWALTOSKI, D. C. C. K. Arquitetura escolar, o projeto do ambiente de ensino. São Paulo: Oficina de Textos, 2011.

KOWALTOSKI, D. C. C. K. et al. Melhoria do conforto ambiental em edificações escolares estaduais de Campinas - SP. Campinas, 2001. Relatório (Pesquisa Científica Fapesp) - Faculdade de Engenharia Civil, Arquitetura e Urbanismo, Universidade de Campinas, Campinas, 2001.

LIPPMAN, P. C. Advancing concepts about activity settings within learning environments. CAE Quartely Newsletter. AIA Committee on Architecture for Education, 2003.

LITTLEFIELD, D. Manual do arquiteto: planejamento, dimensionamento e projeto. Porto Alegre: Bookman, 2011.

MANDAL, A. C. Work-chair with tilting seat. Ergonomics, v. 19, n. 2, p. 157-64, 1976.

MANN, B. L. The evolution of multimedia sound. Computers \& Education, v. 25, p. 1157-1173, 2008.

MORAN, J. Educação Híbrida, um conceito-chave para educação hoje. In: BACICH, L.; TANZI NETO, A.; TREVISANI, F. M. (orgs.) Ensino Híbrido: personalização e tecnologia na educação. Penso, p. 23-42, 2015.

NAIR, P. Blueprint for tomorrow: tedesigning schools for student-centered learning. Cambridge: Harvard Education Press, 2014.

NAIR, P.; FIELDING, R.; LACKNEY, J. The Language of School Design: design patterns for 21st century schools. $3^{\text {rd }}$. ed. Minneapolis: Designshare.com, 2013.

NEUFERT, E. Arte de projetar em arquitetura. São Paulo: Gustavo Gili, 2013.

NEW YORK STATE DEPARTAMENT OF HEALTH. Classroom design standards. New York: NYSDH, 2010.

NIES, J.; HOUGSTED, S. Z-shaped classroom supports technology, enhances learning. School planning and management, v. 36, p. 34-36, 1997.

NOWAKOWSKI, P. Ergonomic shaping of learning places for school children. In: INTERNATIONAL CONFERENCE ON APPLIED HUMAN FACTORS AND ERGONOMICS, 3., Miami, 2010. Proceedings [...] Miami: AHFE, 2010.

ORGANIZATION FOR ECONOMIC CO-OPERATION AND DEVELOPMENT. Education at a Glance 2018, OECD Indicators, Brazil. Brasília: OECD Publishing, 2018. Disponível em: https://read.oecdilibrary.org/education/education-at-a-glance-2018/brazil_eag-2018-73-en\#page6. Acesso em: 15 jan. 2019.

PANERO, J. Dimensionamento humano para espaços interiores. 2. ed. Barcelona: Gustavo Gili, 2016. PRESIDENCIA DA REPÚBLICA. CASA CIVIL. Lei n. 8.666 de 21 de Junho de 1993. Brasília, 1993. PRESIDENCIA DA REPÚBLICA. CASA CIVIL. Decreto n. 7.892 de 23 de Janeiro de 2013. Brasília, 2013.

POLLOCK, C.; STRAKER, L. Information and communication technology in schools. In: LUEDER, R.; BERG RICE V. J. (eds.). Ergonomics for Children: designing products and places for toddlers to teens. Boca Raton: Taylor \& Francis, 2008.

POWELL, M. A. Reacting to classroom design: a case study of how corrective actions impact undergraduate teaching and learning. 2015. Tese (Doutorado em Estudos de Educação) - Lesley University, 2015.

ROGERS, C.; FREIBERG, H. J. Freedom to learn. $3^{\text {rd }}$. ed. Columbus: Merrill, 1994.

SANOFF, H. A visioning process for designing responsive schools. Washington, DC: National Clearinghouse for Educational Facilities, 2001. Disponível em: http://www.edfacilities.org.2001. Acesso em: 5 fev. 2016. 
SANTIAGO, Zilsa M. P. Arquitetura e instrução pública: a reforma de 1922, concepção de espaços arquitetônicos e formação dos primeiros grupos escolares no Ceará. Fortaleza: Edições UFC, 2017. Coleção de História da Educação.

SECRETARIA ESTADUAL DE SAÚDE DE SÃO PAULO. Resolução SS-493, de 8/9/94. Norma técnica de elaboração de projetos de edificações de escolas de $1^{\circ}$ e $2^{\circ}$ grau no Estado de São Paulo. São Paulo, 1994.

SEEP, B. et al. Acústica de salas de aula. New York: Universidade do Kansas. Comitê Técnico em Acústica Arquitetônica, Sociedade Americana em Acústica, 2002.

SLEEGERS, P. et al. Lighting affects students' concentration positively: findings from three Dutch studies. Lighting Research Technology, v. 45, n. 2, p.159-75, 2013.

SIBILIA, P. Redes ou paredes: a escola em tempos de dispersão. Rio de Janeiro: Contraponto, 2012.

SOUZA, L. N. de. Arquitetura escolar, parâmetros de projeto e modalidades de aprendizagem. Campinas, 2018. Dissertação (Mestrado em Arquitetura e Urbanismo) - Faculdade de Engenharia Civil, Arquitetura e Urbanismo, Universidade Estadual de Campinas, Campinas, 2018.

SOUZA, L. N. de; KOWALTOWSKI, D. C. C. K. Importance of learning modalities in the comfort of school architecture. In: ENCONTRO NACIONAL DE CONFORTO NO AMBIENTE CONSTRUÍDO, 14., Camboriú, 2017. Anais [...] Camboriú: ANTAC, 2017.

TAYLOR, A. P. Linking architecture and education: sustainable design for learning environments. New Mexico: University of New Mexico Press, 2009.

TANNER, C. K. Effects of school design on student outcomes. Journal of Educational Administration, v. 47, n. 3, p. 381-399, 2009.

THAPA, A. et al. A review of school climate research. Review of Educational Research, v. 83, n.3, p. 357385, 2013.

THORNBURG, D. Campfire in cyberspace. Lake Barrington: Starsong, 1999.

TIBURCIO, T. Improving learning environment. In: ICL INTERNATIONAL CONFERENCE - AMBIENT AND MOBILE LEARNING, Villach, 2005. Proceedings [....] Villach, 2005.

TIBURCIO, T. Mudanças e desafios na arquitetura da sala de aula: o impacto da tecnologia. In:

ENCONTRO NACIONAL DE TECNOLOGIA DO AMBIENTE CONSTRUÍDO, 8., Fortaleza, 2008.

Anais [...] Fortaleza: UFC, ANTAC, 2008.

VÁSQUEZ, N. G.; PEREIRA, F. O. R.; KUHNEN, A. Preferências visuais das crianças em salas de aula de educação infantil: uma aproximação experimental. Ambiente Construído, Porto Alegre, v. 18, n. 3, p. 1128, jul./set. 2018.

VILLAROUCO, V. An ergonomic look at the work environment. In: INTERNATIONAL ERGONOMICS ASSOCIATION CONGRESS, 17., Beijing, 2009. Proceedings [...] Beijing: IEA, SPRINGER, 2009.

YEN, J. C.; LEE, C.Y. Exploring problem solving patterns and their impact on learning achievement in a blended learning environment. Computers \& Education, v. 56, p. 138-145, 2011. 


\section{Thaisa Sampaio Sarmento}

Faculdade de Arquitetura e Urbanismo | Universidade Federal de Alagoas | Av. Lourival Melo Mota, s/n, Tabuleiro do Martins | Maceió AL - Brasil | CEP 57072-900 | Tel.: (82) 3214-1283 | E-mail: thaisa.sampaio@fau.ufal.br

\section{Vilma Villarouco}

Programa de Pós-Graduação em Design | Universidade Federal de Pernambuco | Av. da Arquitetura, s/n, Cidade Universitária | Recife PE - Brasil | CEP 50740-550 | Tel.: (81) 2126-8319 | E-mail: vvillarouco@gmail.com

Alex Sandro Gomes

Centro de Informática | Universidade Federal de Pernambuco | Av. J ornalista Anibal Fernandes, s/n, Cidade Universitária | Recife - PE Brasil | CEP 50740-560 | Tel.: (81) 2126-8430| E-mail: asg@cin.ufpe.br

\section{Ambiente Construído}

Revista da Associação Nacional de Tecnologia do Ambiente Construído

Av. Osvaldo Aranha, 99 - 3o andar, Centro

Porto Alegre - RS - Brasil

CEP $90035-190$

Telefone: +55 (51) 3308-4084

Fax: +55 (51) 3308-4054

www. seer. ufrgs. br/ ambienteconstruido

E-mail: ambienteconstruido@ufrgs.br

(c) (i)

This is an open-access article distributed under the terms of the Creative Commons Attribution License. 